\title{
Do lake littoral benthic invertebrates respond differently to eutrophication, hydromorphological alteration, land use and fish stocking?
}

\author{
Rebeka Šiling* and Gorazd Urbanič \\ Institute for Water of the Republic of Slovenia, Dunajska cesta 156, 1121 Ljubljana, Slovenia
}

\begin{abstract}
In order to provide adequate guidelines in freshwater management, managers need reliable bioindicators that can respond differently to varied stressors. Managers also have to consider hierarchical structure of environmental factors. Thus, our research aims to test the independence of taxa responses along environmental gradients and to examine in what order natural and anthropogenic factors constrain the structure of littoral benthic assemblages. The rank of explained variance of littoral benthic assemblage's variable group hierarchy was: land use $>$ landscape characteristics $>$ eutrophication $>$ fish stocking $>$ hydromorphological alteration. We determined nine gradients (two natural and seven stressor gradients), separated into five groups based on statistically significant differences in responsiveness of taxa. Apart from responsiveness to natural factors, littoral benthic invertebrates could be used as bioindicators for stressors reflecting urbanization, eutrophication, hydromorphological alteration and fish stocking. The taxonomical composition of littoral benthic invertebrates, especially when taxa with preference for certain relatively narrow environmental conditions along gradients are present, can be used to identify effects of key stressors. Our findings have profound implications for ecological assessment and management of lakes, as they indicate that benthic invertebrates can be used when the effects of multiple stressors need to be disentangled.
\end{abstract}

Keywords: macroinvertebrates / multiple stressors / bioindication / lakes / multihabitat sampling

Résumé - Est-ce que les invertébrés benthiques d'un littoral lacustre réagissent différemment à l'eutrophisation, la modification hydromorphologique, l'utilisation des terres et l'empoissonnement ? Afin de fournir des lignes directrices adéquates en matière de gestion d'écosystèmes d'eau douce, les gestionnaires ont besoin de bioindicateurs fiables qui puissent répondre différemment à des facteurs de stress variés. Les gestionnaires ont également à considérer la structure hiérarchique des facteurs environnementaux. Ainsi, notre recherche vise à tester l'indépendance des réponses des taxons le long de gradients environnementaux et d'examiner dans quel ordre les facteurs naturels et anthropiques influent sur la structure des assemblages benthiques littoraux. L'ordre dans la variance expliquée du groupe des variables de l'assemblage benthique littoral était : l'utilisation des terres $>$ les caractéristiques du paysage $>$ l'eutrophisation $>$ l'empoissonnement $>$ l'altération hydromorphologique. Nous avons déterminé neuf gradients (deux naturels et sept gradients de stress), séparés en cinq groupes en fonction des différences statistiquement significatives dans la réactivité des taxons. En dehors de la réactivité à des facteurs naturels, les invertébrés benthiques du littoral pourraient être utilisés comme bioindicateurs pour les facteurs de stress reflétant l'urbanisation, l'eutrophisation, l'altération hydromorphologique et l'empoissonnement. La composition taxinomique des invertébrés benthiques littoraux, en particulier lorsque les taxons, avec une préférence pour certaines conditions environnementales relativement importante, sont présents le long des gradients, peut être utilisée pour identifier les effets des principaux facteurs de stress. Nos résultats ont des implications profondes pour l'évaluation et la gestion écologique des lacs, car ils indiquent que les invertébrés benthiques peuvent être utilisés lorsque les effets de multiples facteurs de stress doivent être dissociés.

Mots clés : macroinvertébrés / facteurs multiples de stress / bioindication / lac / échantillonnage multihabitat

\footnotetext{
* Corresponding author: rebeka.siling@izvrs.si
} 


\section{Introduction}

Freshwater ecosystems are subject to accelerated rates of transformations and are some of the most endangered types of ecosystems in the world (Monroe et al., 2009). In order to address this problem international laws, such as the European Water Framework Directive (WFD) (European Union, 2000), attempt to regulate and protect water bodies through the assessment and management of human-caused stressors (e.g., land use, release of chemical toxins, nutrient loading) in freshwater ecosystems (Allan, 2004; Schinegger et al., 2012; Verdonschot et al., 2013). Since multiple human activities contribute to environmental degradation (Crain et al., 2008; Bozelli et al., 2009), we need to understand the relative influences of these different activities in order to optimize freshwater management. Accordingly, management of freshwaters has been approved through development of bioassessment programs using different biotic indicators (Borisko et al., 2007; Johnson and Hering, 2009).

Factors operating across a wide range of spatial and temporal scales can impact the structure and function of vulnerable aquatic assemblages (Johnson et al., 2006; Sandin and Solimini, 2009; Li et al., 2010). Therefore, a common approach for freshwater ecosystem assessment uses aquatic assemblages grouped according to their perceived tolerance to different environmental factors (Yuan, 2004; Mazzoni et al., 2014). This generally involves determining taxon tolerance (sensitivity) values (scores) and calculating ratios of disturbance sensitive taxa to insensitive taxa (Solimini et al., 2006; Donohue et al., 2009a; Urbanič, 2014a). If measured environmental variables reflect different anthropogenic disturbance gradients, then species scores can help to identify the effects of different types of anthropogenic stressors (EPA, 2006).

Benthic invertebrates are commonly used in bioassessment when considering the wide range of natural habitat preferences, high biodiversity and high sensitivity to diverse environmental factors (Sandin and Johnson, 2000; Jyväsjärvi et al., 2011; 2012; Miler et al., 2014). Associations have been demonstrated between benthic invertebrates and variables such as submerged plant abundance (Hanson et al., 2012), substratum (Donohue and Irvine, 2003), total phosphorus, chlorophyll a (O'Toole et al., 2008), dissolved oxygen concentration (Williams, 1996), water level variability (Zohary and Ostrovsky, 2011) and availability of food resources and interspecific interactions among benthic invertebrates, such as competition and predation (Walker, 1998). Benthic invertebrates integrate the effects of various stressors, including hydromorphological changes, due to their long life cycles and low mobility, and as such may have a substantial practical advantage over other aquatic assemblages as indicator organisms (Friberg, 2014).

Whereas consolidated ecological studies based on benthic invertebrates exist for rivers (e.g., Longing et al., 2010; Pavlin et al., 2011; Petkovska and Urbanič, 2015), fewer similar studies exist for assessment of the ecological quality of lakes (e.g., Nõges, 2009; Jyväsjärvi et al., 2011), and even fewer studies have examined littoral benthic invertebrates (e.g., Solimini et al., 2006; Pilotto et al., 2015). Settlement on lake shores and numerous activities makes the littoral a highly threatened zone in lakes (Vadeboncoeur et al., 2001;
Jenkins, 2003; Peterlin and Urbanič, 2013). Anthropogenic disturbances, such as eutrophication (White and Irvine, 2003; Donohue et al., 2009b; Bazzanti et al., 2012), fish stocking (Pierce and Hinrichs, 1997; Leppä et al., 2003), hydromorphological alterations (Gabel et al., 2012; Jurca et al., 2012; Peterlin and Urbanič, 2013; McGoff et al., 2013; Urbanič, 2014b) and land use (McGoff and Sandin, 2012), may have profound effects more on the littoral zone than the profundal, and thus warrant closer considerations in lake assessments.

To fully understand the extent to which anthropogenic disturbances affect littoral benthic assemblages, it is important to understand their relationships to the environmental factors that provide the basic ecological template structuring the assemblages. Studies on species-environment relationships can also help tease apart the anthropogenically derived disturbances from the influence of natural landscape features. Identifying the relative importance of different environmental factors on littoral benthic assemblages can help prioritize management and restoration actions. We hypothesized that littoral benthic invertebrates are sensitive enough to serve as bioindicators of changes in environmental conditions. To test this hypothesis we aim to:

- examine in what order do natural and anthropogenic factors of different spatial scales constrain the distribution of littoral benthic invertebrates in lakes,

- determine group-specific environmental gradients: landscape characteristics, land use, eutrophication, fish stocking and hydromorphological alteration, and investigate the differences among responses of benthic invertebrates along environmental gradients in order to identify stressors whose effects can be disentangled using benthic invertebrates, and

- evaluate bioindication potential of littoral benthic invertebrate taxa to recognized environmental gradients through their preference for certain relatively narrow environmental conditions (i.e., sensitivity).

\section{Materials and methods}

\subsection{Study area and sampling}

We included all lakes that are part of the assessment system development program for the implementation of the WFD in Slovenia (European Union, 2000). Two lakes are natural in origin and eleven are constructed lakes, which provide various ecosystem services, such as sports fishing, flood protection or irrigation. The investigated lakes are located from lowlands to the mountain foothills, and they differ considerably in their characteristics (Fig. 1, Tab. 1). Altogether, we collected data from 13 lakes (comprising 114 sites) between 2006 and 2012. Benthic invertebrate data and physico-chemical parameters were collected in the same years. However, benthic invertebrates were collected in the summer months (July-August), whereas water for physico-chemical analyses was collected four times a year in a vegetation season (March-October/November). All data were obtained as part of the national monitoring and assessment system development programs of Slovenia (e.g., Remec Rekar, 2009; Urbanič et al., 2013).

We sampled benthic invertebrates using a proportional stratified sampling approach in the littoral zones 


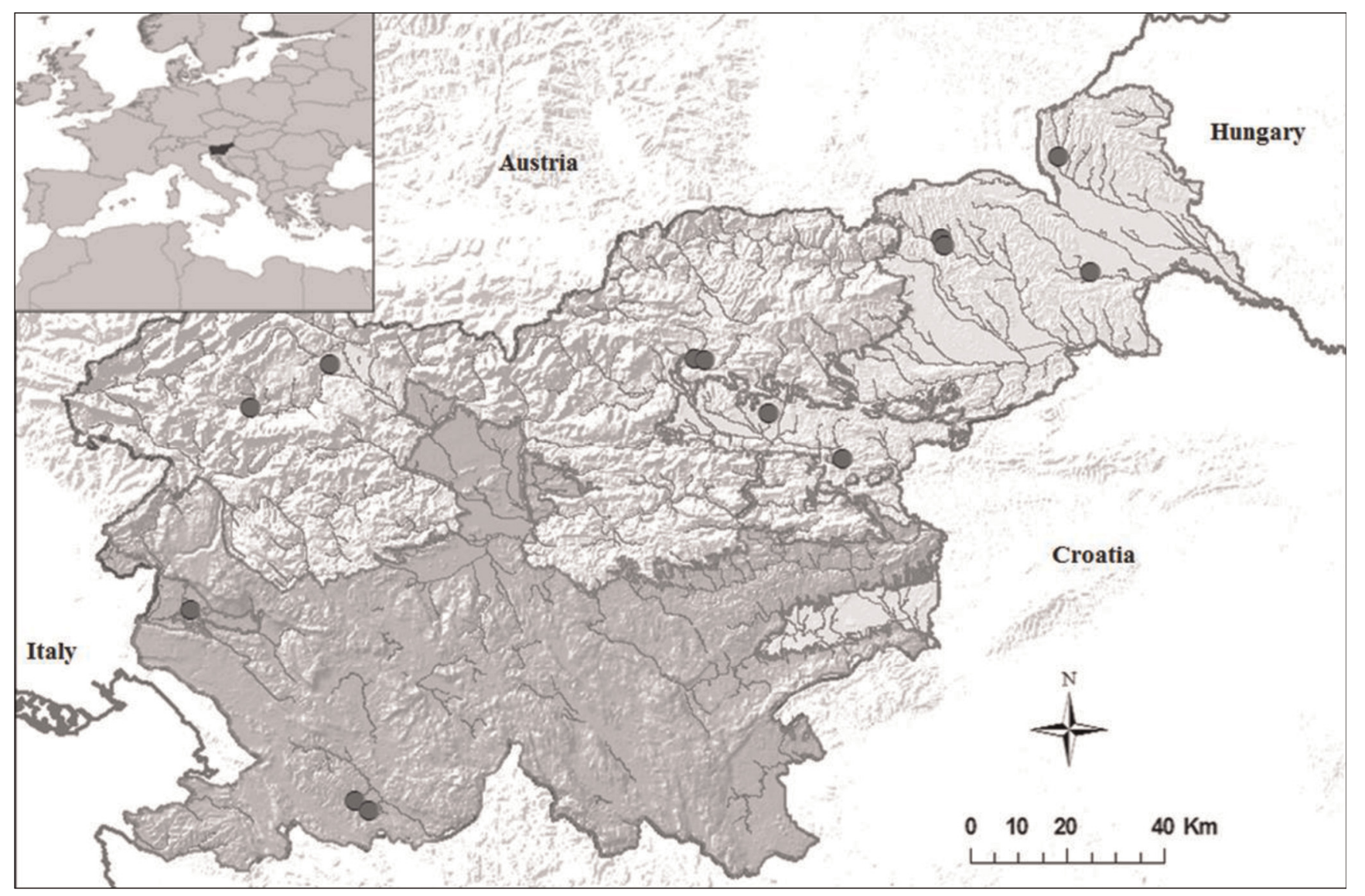

Fig. 1. Locations of study lakes in Slovenia.

Table 1. Characteristics of study lakes.

\begin{tabular}{lllllrrrrr}
\hline Lake & Size $\left(\mathrm{km}^{2}\right)$ & Catc $\left(\mathrm{km}^{2}\right)$ & Mean_dp $(\mathrm{m})$ & t_ret (days) & TP $(\mu \mathrm{g} / \mathrm{L})$ & I-AG $(\%)$ & NAT $(\%)$ & No. Sam. 1 & No. Sam. 2 \\
\hline Bled & 1.43 & 6.5 & 19 & 548 & $10-16$ & 4 & 66 & 26 & 5 \\
Bohinj & 3.28 & 94.3 & 28 & 146 & $3-11$ & 0 & 98 & 28 & 4 \\
Družmirje & 0.70 & 32.1 & 24 & 463 & 22 & 6 & 68 & 3 & 1 \\
Gajševci & 0.77 & 124.5 & 3 & 4 & $99-222$ & 57 & 32 & 8 & 3 \\
Klivnik & 0.36 & 7.8 & 9 & 214 & $9-12$ & 26 & 67 & 5 & 2 \\
Ledava & 2.18 & 108.1 & 3 & 49 & $64-135$ & 50 & 36 & 8 & 3 \\
Mola & 0.68 & 20.7 & 6 & 74 & $19-22$ & 19 & 67 & 5 & 2 \\
Pernica 1 & 0.66 & 127.7 & 3 & 60 & $80-224$ & 42 & 25 & 3 & 3 \\
Pernica 2 & 0.57 & 127.7 & 3 & 13 & $80-224$ & 42 & 25 & 5 & 2 \\
Slivnica & 0.84 & 30.1 & 5 & 63 & $33-86$ & 34 & 45 & 5 & 2 \\
Šmartno & 1.07 & 12.4 & 6 & 347 & $33-96$ & 30 & 46 & 11 & 3 \\
Velenje & 1.35 & 20.4 & 19 & 885 & $22-52$ & 12 & 58 & 6 \\
Vogrsko & 0.82 & 10.9 & 10 & 41 & $8-46$ & 29 & 49 & 9 & 2 \\
\hline
\end{tabular}

Size-lake surface area, Catc-catchment area, Mean_dp-mean depth, t_ret-retention time, $\mathrm{TP}$ - minimum and maximum value of mean annual range total phosphorous concentration, I-AG-percentage of intensive agricultural land use in the catchment, NAT - percentage of natural areas in the catchment, No. Sam. 1 -number of samples included in survey and No. Sam. 2 pooled samples as lake-year.

(Urbanič et al., 2012). Sampling was conducted once a year for each lake in different years: Bled and Bohinj were sampled in 2006, 2007, 2008 and 2010; Gajševci, Ledava, Šmartno, Pernica 1 and Pernica 2 were sampled in 2006, 2007 and 2011; Klivnik and Mola in 2007 and 2012, Slivnica in 2007, 2012; Družmirje in 2011, Velenje in 2009 and 2011 and Vogršček in
2006, 2007 and 2012. Selection of sampling sites in natural lakes was determined according to the proportion of hydromorphologically changed shoreline, which is expressed in classes of LMI, whereas in artificial lakes the determination was based on lakeshore characteristics. Each sampling site covered an area of $10 \mathrm{~m}$ lakeshore length and toward the open 
water to $1 \mathrm{~m}$ depth or until a distance of $10 \mathrm{~m}$ was reached. To define depth strata, we divided the sampling sites into four water-depth classes: $<0.25 \mathrm{~m}$ depth, $0.26-0.50 \mathrm{~m}, 0.51-0.75 \mathrm{~m}$ and $>0.75 \mathrm{~m}$ depth. We defined the substrate categories according to the AQEM consortium (2002) with modifications for defining substrate types/strata following Urbanič (2014a). Substrate microhabitat types were defined as a combination of depth class and substrate category, scaled proportionately to their coverage at the sampling sites.

At each sampling site, we sampled benthic invertebrates in microhabitat types that covered at least $10 \%$ of the area. Each invertebrate sample was collected using a $500 \mu \mathrm{m}$ mesh-size hand net and consisted of ten sampling units of an area of $0.625 \mathrm{~m}^{2}$. We preserved samples in the field using $4 \%$ formaldehyde solution. We identified all benthic invertebrates to the lowest possible taxonomic level (usually to species or genus except for Chironomidae and Tubificidae, which were identified to family or sub-family) and determined abundances by counting all organisms from the sample. We subsequently stored all invertebrates in $70 \%$ ethanol.

\subsection{Environmental variables}

Composite samples were taken four times a year to measure eutrophication parameters (total phosphorus concentration, Secchi depth, orthophosphate concentration, nitrate concentration, ammonium concentration, total nitrogen concentration and chlorophyll $a$ ) and mean annual values were calculated prior to analysis. At the time of invertebrate sampling, we also simultaneously measured physico-chemical parameters such as water temperature, conductivity, $\mathrm{pH}$, dissolved oxygen concentration and dissolved oxygen saturation. All analysis and measurements of physico-chemical parameters followed protocols in the Official Gazette of the Republic of Slovenia, which conform to international standards (e.g., ISO) (OGRS, 2009). For each sampling site, we calculated the Lakeshore modification index (LMI) (Peterlin and Urbanič, 2013) and percentage of substrate category coverage. We created four new variables combining substrate categories. To generate a lithal variable, we summed up coverage percentages of megalithal, macrolithal, mesolithal and microlithal. To generate a fine substrate variable we summed coverage percentages of akal, psammopelal, pelal and psammal substrate. To generate a phytal variable, we summed coverage percentages of macrophytes, macroalgae and filamentous bacteria. Fine particulate matter, coarse particulate matter and debris were combined to generate a particulate organic matter variable. We also determined the percentage of land use types in the lakes' catchments. Variables describing land use in catchments were calculated with GIS tools, using the Corine Land Cover classification (CLC, 2006). We distinguished six categories of land use: natural areas (CLC categories 3.4 and 5), urban areas (CLC class 1), areas with extensive agriculture (CLC categories 2.3.1 and 2.4.3), areas with intensive agricultural practice (CLC categories 2.1, 2.2 and 2.4.2), arable land (CLC categories 2.1.1 and 2.4.2) and land use defined as plantations (CLC categories 2.2.1 and 2.2.2). The Fisheries Research Institute of Slovenia provided the information on stocked fish species and their biomass for each lake-year. We then calculated the number of stocked fish species and biomass of stocked fish species feeding types. For fish species feeding types we used information from Dußling et al. (2004). Altogether we extracted a set of 38 environmental variables, which have previously been shown to shape benthic invertebrates assemblages. Based on the range of multiple stressors affecting lakes worldwide (Stendera et al., 2012), we divided the variables into five groups: landscape characteristics, land use, hydromorphological alteration, eutrophication and fish stocking (Tab. 2). We selected landscape characteristic variables as parameters unaffected by humans (e.g., altitude and lake size) and other variables as parameters affected by humans (stressors). In an individual stressor group, we included variables of different spatial scales. In order to elucidate contribution of pseudo replication of lake-level and catchment-level variables, we split our data in two sub-sets. One subset represented hydromorphological alteration variables for single sampling sites (122 samples) and abundances of benthic invertebrates at these sites. In the second subset, we pooled data of lake- and catchment-level variables to lake-year units. Together we had 32 samples for single lake-level or catchment-level variables, including averaged abundances of benthic invertebrates. We calculated separate Spearman correlation coefficients within each group of environmental variables (Tab. 2) in order to identify and exclude strongly correlated variables (Rs $>0.75)$. Correlation coefficients (Appendix 1) were calculated using the software package $\mathrm{R}$ version 3.2.1 (R Development Core Team, 2011). Statistical analysis revealed strong correlations among variables within each group. Lake mean depth and both maximum depth $(\mathrm{Rs}=0.95 ; p<0.001)$ and lake volume $(\mathrm{Rs}=0.81 ; p<0.001)$ strongly correlated. After exclusion of lake volume and maximum depth, five variables were included in the landscape characteristic group. Within the group of variables reflecting eutrophication, strong correlations were found for total phosphorus and both Secchi depth $(\mathrm{Rs}=-0.86 ; p<0.001)$ and chlorophyll $a(\mathrm{Rs}=0.85 ; p<0.001)$. Secchi depth and chlorophyll $a$ respond to nutrient concentrations and were thus excluded. Five variables of water phosphorous and nitrogen compounds comprised the eutrophication group. Among land use variables, strong correlations were found between intensive agriculture and arable land (Rs $=0.99 ; p<0.001)$ and a strong negative correlation was found between intensive agricultural and natural land use $(\mathrm{Rs}=-0.91 ; p<0.001)$. Thus, four variables remained in the land use group. Within the group of hydromorphological alteration variables, the strongest correlation was between LMI and Shoreline alteration $(\mathrm{Rs}=0.77 ; p<0.001)$. After exclusion of Shoreline alteration, the hydromorphological alteration group consisted of ten variables-six describing substrate and four LMI values calculated for different lakeshore zones. There was one strong correlation among variables representing fish stocking: omnivorous fish and biomass of stocked fish $(\mathrm{Rs}=0.82$; $p<0.001)$. In the fish stocking group, we included five variables: four representing fish feeding groups and one representing number of stocked fish species.

\subsection{Statistical analysis}

We conducted five environmental group-specific partial canonical correspondence analyses (pCCA) to determine the relationship of littoral benthic assemblages (dependent variables) to environmental factors (independent variables) with 
R. Šiling and G. Urbanič : Knowl. Manag. Aquat. Ecosyst. 2016, 417, 35

Table 2. Five groups of environmental variables included in Spearman correlation analysis (Abbrev.-abbreviation, Med-median, Min-minimum and Max-maximum) and the data transformations that we applied (Trans.).

\begin{tabular}{|c|c|c|c|c|c|c|c|}
\hline Group & Variable & Abbrev. & Unit & Med & Min & Max & Trans. \\
\hline \multirow{7}{*}{$\begin{array}{l}\text { Landscape } \\
\text { characteristics }\end{array}$} & Altitude & (Alt) & $\mathrm{m}$ & 292 & 101 & 526 & \\
\hline & *Max depth & (Max_dp) & $\mathrm{m}$ & 17 & 4 & 87 & $\ln (x+1)$ \\
\hline & Mean depth & (Mean_dp) & $\mathrm{m}$ & 7 & 3 & 28 & $\ln (x+1)$ \\
\hline & *Volume & $(\mathrm{Vol})$ & $\mathrm{m}^{3} * 10^{6}$ & 6.5 & 1.2 & 92.4 & $\ln (x+1)$ \\
\hline & Lake size & (Size) & $\mathrm{km}^{2}$ & 0.96 & 0.36 & 3.28 & $\ln (x+1)$ \\
\hline & Catchment size & (Catc) & $\mathrm{km}^{2}$ & 25.4 & 6.5 & 127.7 & $\ln (x+1)$ \\
\hline & Retention time & (t_ret) & days & 110 & 4 & 885 & $\ln (x+1)$ \\
\hline \multirow{11}{*}{$\begin{array}{l}\text { Hydromorphological } \\
\text { alteration }\end{array}$} & Littoral zone & (Z_Litt) & & 0.35 & 0.00 & 0.85 & \\
\hline & *Shoreline zone & (Z_Shor) & & 0.00 & 0.00 & 0.75 & \\
\hline & Riparian zone & (Z_Rip) & & 0.25 & 0.00 & 1.00 & \\
\hline & Lake shore zone & (Z_LShor) & & 0.25 & 0.00 & 1.00 & \\
\hline & Lakeshore modification index & $(\mathrm{LMI})$ & & 0.89 & 0.15 & 2.66 & \\
\hline & Lithal & & & 44 & 0 & 100 & $\arcsin (\operatorname{sqrt} x)$ \\
\hline & FineSubs & & & 0 & 0 & 98 & $\arcsin (\operatorname{sqrt} x)$ \\
\hline & Argyllal & & & 0 & 0 & 99 & $\arcsin (\operatorname{sqrt} x)$ \\
\hline & Phytal & & & 3 & 0 & 100 & $\arcsin (\operatorname{sqrt} x)$ \\
\hline & Xylal & & & 1 & 0 & 60 & $\arcsin (\operatorname{sqrt} x)$ \\
\hline & POM & & & 1 & 0 & 90 & $\arcsin (\operatorname{sqrt} x)$ \\
\hline \multirow{7}{*}{ Land use } & Urbanization & (URBAN) & $\%$ & 1 & 0 & 11 & $\arcsin (\operatorname{sqrt} x)$ \\
\hline & Intensive agriculture & $(\mathrm{I}-\mathrm{AG})$ & $\%$ & 29 & 0 & 57 & $\arcsin (\operatorname{sqrt} x)$ \\
\hline & Extensive agriculture & $(\mathrm{E}-\mathrm{AG})$ & $\%$ & 19 & 1 & 31 & $\arcsin (\operatorname{sqr} t x)$ \\
\hline & *Arable land & $(\mathrm{FIE})$ & $\%$ & 25 & 0 & 54 & $\arcsin (\operatorname{sqrt} x)$ \\
\hline & Plantations & $(\mathrm{PLANT})$ & $\%$ & 0 & 0 & 11 & $\arcsin (\operatorname{sqrt} x)$ \\
\hline & *Natural areas & (NAT) & $\%$ & 49 & 25 & 99 & $\arcsin (\operatorname{sqrt} x)$ \\
\hline & Piscivorous & (Pisci) & $\mathrm{kg} / \mathrm{ha}$ & 3.36 & 0 & 18.53 & $\ln (x+1)$ \\
\hline \multirow{6}{*}{ Fish stocking } & Omnivorous & (Omni) & $\mathrm{kg} / \mathrm{ha}$ & 3.57 & 0.00 & 1000 & $\ln (x+1)$ \\
\hline & Invertivorous-Piscivorous & (InvPisci) & $\mathrm{kg} / \mathrm{ha}$ & 0.11 & 0.00 & 21.33 & $\ln (x+1)$ \\
\hline & Invertivorous & (Inv) & $\mathrm{kg} / \mathrm{ha}$ & 0.01 & 0.00 & 11.38 & $\ln (x+1)$ \\
\hline & Herbi- and planktivorous & (HerPlank) & $\mathrm{kg} / \mathrm{ha}$ & 0.00 & 0.00 & 2.38 & $\ln (x+1)$ \\
\hline & *Stocked biomass & $(\mathrm{kg} / \mathrm{ha})$ & $\mathrm{kg} / \mathrm{ha}$ & 14.89 & 0.00 & 1000 & $\ln (x+1)$ \\
\hline & Number of fish species & (NoFishSp) & number & 6.00 & 0.00 & 14.00 & \\
\hline \multirow{7}{*}{ Eutrophication } & $*$ Secchi depth & $(\mathrm{SecD})$ & $\mathrm{cm}$ & 1.96 & 0.22 & 9.78 & $\ln (x+1)$ \\
\hline & Total phosphorous & $(\mathrm{TP})$ & $\mu g \mathrm{PO}_{4}-\mathrm{P} / 1$ & 27.7 & 3.5 & 224.0 & $\ln (x+1)$ \\
\hline & Orthophosphate & $\left(\mathrm{PO}_{4}\right)$ & $\mu \mathrm{g} \mathrm{PO}_{4}-\mathrm{P} / 1$ & 2.5 & 0.8 & 191.8 & $\ln (x+1)$ \\
\hline & Nitrate & $\left(\mathrm{NO}_{3}\right)$ & $\mu \mathrm{g} \mathrm{NO}_{3}-\mathrm{N} / 1$ & 0.59 & 0.14 & 4.53 & $\ln (x+1)$ \\
\hline & Ammonium & $\left(\mathrm{NH}_{4}\right)$ & $\mu \mathrm{g} \mathrm{NH}_{4}-\mathrm{N} / 1$ & 108 & 5 & 811 & $\ln (x+1)$ \\
\hline & Total nitrogen & $(\mathrm{TN})$ & $\mathrm{mg} \mathrm{N} / 1$ & 0.80 & 0.08 & 6.95 & $\ln (x+1)$ \\
\hline & ${ }^{*}$ Chlorophyll $a$ & (Chl_a) & $\mu \mathrm{g} / 1$ & 5.8 & 0.9 & 61.4 & $\ln (x+1)$ \\
\hline
\end{tabular}

* Indicate variables which were excluded after Spearman correlation analysis.

removed spatial and/or temporal effects (covariables). When the effects of covariables are omitted from the pCCA, we are able to explain taxa variability and show important patterns of variation in the benthic invertebrate assemblage composition on account of the selected variables. To consider spatial and temporal dependence structure, latitude and longitude of the sampling sites in the Slovenian national grid and sampling year, respectively, were used as covariables (Zuur et al., 2010). All samples were collected in the summer season, and thus season was not considered. We used lake-year data to conduct four pCCA separately using the following groups of environmental variables: landscape characteristics, fish stocking, eutrophication and land use, and sampling year as a covariable. A subset with 122 benthic invertebrate samples was used in a pCCA with hydromorphological alteration variables and coordinates, with sampling year as the covariable. Prior to analyses, we selected appropriate transformation for each environmental variable to correct for heteroscedasticity in the data, whereas biological data were $\log (x+1)$ transformed (Tab. 2 ). In order to give emphasis to more commonly distributed species, we downweighted rare species. In the pCCA, we used variables that individually significantly $(p<0.1)$ explained a portion of the benthic invertebrate variance after fitting covariables. Thus, the number of environmental variables was 
additionally reduced prior to the pCCA environmental gradient determination. The significance of environmental variables used for littoral benthic invertebrate assemblages was defined with a Monte Carlo permutation test (999 permutations). For each selected variable, the individual contribution to the explained variance of the benthic invertebrate assemblages $\left(\lambda_{1}\right)$ and the environmental group-specific relative portion of considered variables defined as $\mathrm{Rs}=\lambda_{1} / \lambda_{1 \max }$ were calculated. Because we used CANOCO 5 for the pCCA, both environmental groupspecific non-adjusted explained variances and adjusted explained variances of benthic invertebrate assemblages also were calculated (Ter Braak and Šmilauer, 2012). In order to compare taxa environmental gradient preferences, first and second pCCA axes (environmental group specific species scores) were used (Appendix 2). Species scores were normalized to a common scale of 0 to 1 , where 0 indicates the most degraded/ lowest and 1 the pristine/highest value. Prior to normalization, direction of environmental gradient increasing was defined (Fig. 4). Normalisation was done according to equation (1):

$$
\text { Value }=\frac{\mathrm{SC}_{-} \mathrm{CCA}_{\mathrm{e}-\mathrm{i}}-\mathrm{SC}_{-} \mathrm{CCA}_{\mathrm{e}-\mathrm{LA}}}{\mathrm{SC}_{-} \mathrm{CCA}_{\mathrm{e}-\mathrm{REF}}-\mathrm{SC}_{-} \mathrm{CCA}_{\mathrm{e}-\mathrm{LA}}},
$$

where $\mathrm{SC}_{-} \mathrm{CCA}_{\mathrm{e}-\mathrm{i}}$ is the environmental group specific species score (biplot scaling) of the $i$ th taxon and $\mathrm{SC}_{-} \mathrm{CCA}_{\mathrm{e}-\mathrm{REF}}$ is the pristine/highest value of the environmental group specific species score and SC_CCA $\mathrm{e}_{\mathrm{L}-\mathrm{LA}}$ is the most degraded/lowest value of the environmental group specific species score. In calculation of highest and lowest environmental group specific species score, extremes and outliers were not considered. In order to determine the relationship between recognized environmental gradients and littoral benthic assemblage structure in more detail, we determined taxa tolerance values that are frequently used in bioassessment (e.g., Zelinka and Marvan, 1961; Urbanič, 2014b). We determined tolerance values using the pCCA ordination axis species tolerance (root mean squared deviation for species) according to Table 3 . To detect differences in the mean species score values and mean tolerance values among environmental gradients, we used Friedman tests followed by a post-hoc multiple comparison Wilcoxon signed-rank tests. For this type of analyze we used SPSS Statistics 21 (IBM, 2012) for Windows.

\section{Results}

\subsection{Benthic invertebrate assemblages}

A total of 136,358 individuals, representing 253 taxa (Appendix 2) were recorded at the 114 sampling sites and 32 lake-years (Fig. 2). Diptera was the most abundant group $(48,504)$, followed by Oligochaeta $(33,272)$ and Heteroptera $(16,924)$ (Fig. 2). The most diverse group was Coleoptera (37), followed by Diptera and Trichoptera (both 36) (Fig. 2). More than 15 taxa were recorded in each of the following four groups: Oligochaeta (27), Odonata (28), Gastropoda (19) and Ephemeroptera (18). Other groups were less diverse. Differences in diversity also reflected the varied taxonomic resolution of the groups.

\subsection{Effects of environmental gradients}

Gradient analyses were run separately for each variable group with four (land use group) to nine variables (hydro-
Table 3. Determination of tolerance values of 253 taxa $(\mathrm{Tv})$ derived from pCCAs analyses.

\begin{tabular}{lc}
\hline pCCA tolerance values & Tv \\
\hline$<0.4$ & 5 \\
$0.4-0.6$ & 3 \\
$0.6>$ & 1 \\
\hline
\end{tabular}

morphological alteration group) (Tab. 4). The first axis individually and all canonical axis together were statistically significant $(p<0.05)$ in each environmental variable group (Tab. 5). In the land use group, the highest proportion of variation in the benthic invertebrates was explained by intensive agriculture (17.5\%). Other variables of the land use group showed moderate (relative $\lambda_{1}=0.5-0.75$ ) or relatively weak (relative $\lambda_{1}<0.5$ ) explanatory power. In the landscape characteristic group, mean depth explained the highest proportion (16.2\%). Additionally, lake size and altitude showed relatively high (relative $\lambda_{1}>0.75$ ) explanatory power, whereas retention time and catchment size were approximately half as explanatory as mean depth. Total phosphorus (15.4\%) was the best explanatory variable in the eutrophication group. Other variables of that group were moderately explanatory (relative $\lambda_{1}=0.5-0.75$ ). In the fish stocking group, the highest variance of the benthic invertebrates was explained by omnivorous fish (10.3\%). In the hydromorphological alteration group, the variable littoral zone contributed significantly less to explaining variance $(2.5 \%)$, likely because of the higher number of samples, which resulted in higher total inertia (1.995) compared with other environmental groups (1.636). Also, two variables of the hydromorphological alteration group (LMI and lithal) showed relatively high (relative $\left.\lambda_{1}>0.75\right)$ explanation power, whereas all other variables were moderately explanatory.

The partial variation in the benthic macroinvertebrate taxa (253) data was 1.995 using the 122 samples (hydromorphological alteration group) and 1.636 including the 32 lake-years (for all other environmental groups) (Tab. 5). Comparable amounts $(29-38 \%)$ of the total variation in littoral benthic assemblages were explained individually by land use, landscape characteristics, eutrophication and fish stocking variables, whereas hydromorphological alteration variables explained substantially less (14\%) (Fig. 3). Adjusted values of the explained variance revealed bigger differences among variable groups and provided the following ranking scheme: land use $(29 \%)>$ landscape characteristics $(24 \%)>$ eutrophication $(17 \%)>$ fish stocking $(15 \%)>$ hydromorphological alteration $(6 \%)$.

\subsubsection{Landscape characteristics gradients}

Examination of the landscape pCCA ordination diagram indicated two gradients (Fig. 4a). The first landscape gradient represented lake morphometry and explained a majority of the variance in the taxa-environment relationship (53\%). Along the first pCCA axis shallow, small and mostly lowland lakes on the right hand side are separated from the deep, mid-sized and mid-altitude lakes on the left-hand side. Nevertheless, a gradual taxa turnover is found along the lake morphometry 


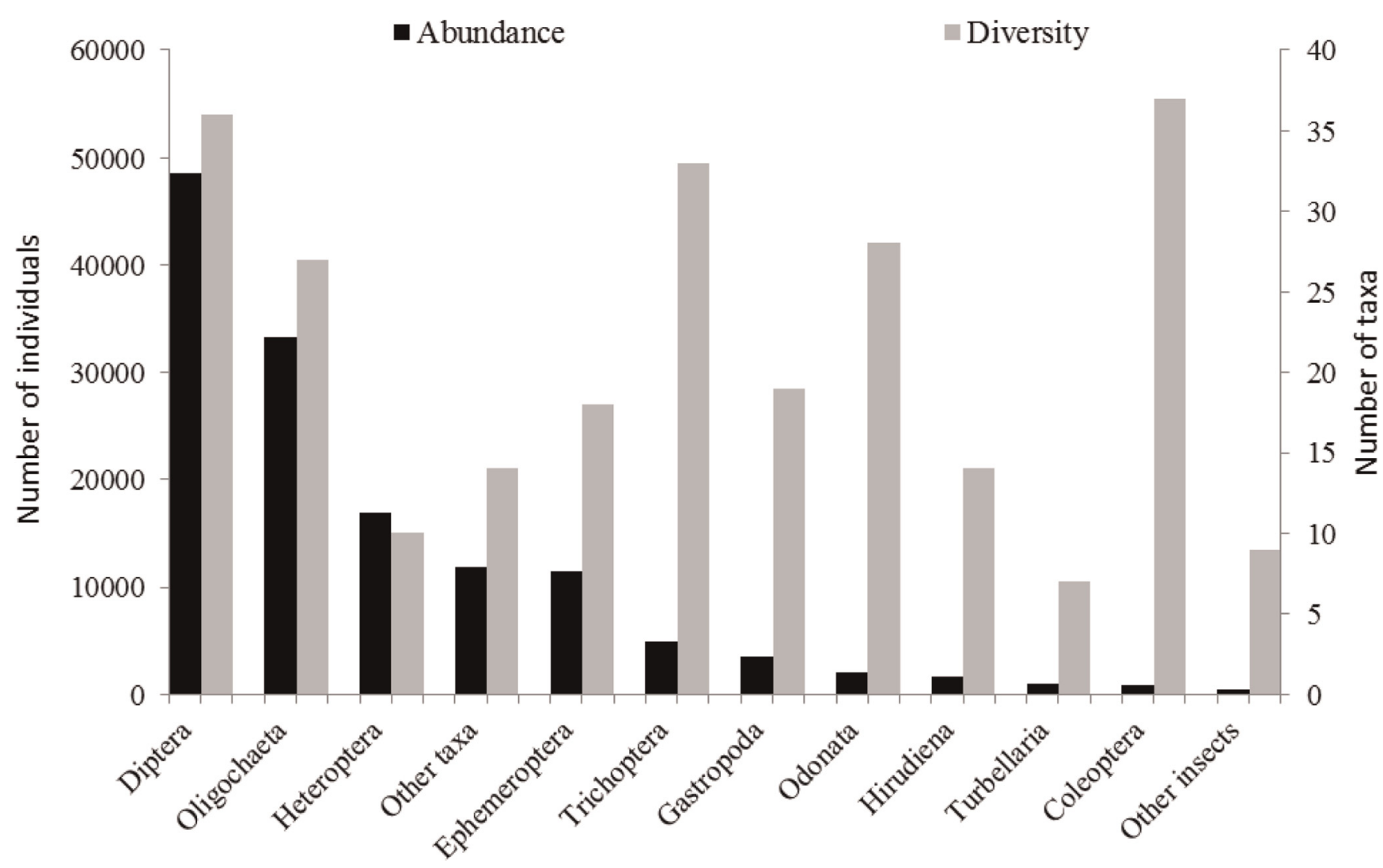

Fig. 2. Abundance (black bars) and diversity (gray bar) composition of major taxonomic groups of littoral benthic invertebrates in the dataset.

gradient. Lake catchment size is reflected by the second pCCA axis ( $23 \%$ of variance explained), and thus separating lakes along the catchment dimension gradient. Lakes with a big catchment area were found in the lower part, whereas lakes with a small catchment area were distributed in the upper part of the ordination plot. Along the second axis, most taxa were distributed in the central part of the ordination plot, showing weak effects of catchment size on specific littoral benthic invertebrate taxa.

\subsubsection{Land use gradients}

Two gradients were determined after inspection of the land use pCCA ordination diagram (Fig. 4b). Intensive agriculture was reflected by the first axis, which explained half of the variance in taxa $(50 \%)$. Along the first pCCA axis, lakes with a high share of intensive agricultural land use and a high share of plantations in lake catchments on the left-hand side are separated from a few lakes with less agricultural land use on right-hand side. Separation of taxa into two groups along the first gradient implies profound effects of agriculture. The second axis indicates a gradient of urbanization (26\% of variance explained). Lakes with a big share of urbanization land use are found in the upper part along second axis, whereas lakes with a small share of urbanization land use are distributed in the middle of the ordination plot. Along the second axis, taxa are mostly distributed in the central part of the ordination plot with few in the upper part, indicating a specific effect of urbanization on specific littoral benthic invertebrate taxa.

\subsubsection{Eutrophication gradients}

Eutrophication pCCA ordination diagram reflected two gradients (Fig. 4c). The first gradient represented nutrients and explained the majority of variance in the taxa-environment relation $(51 \%)$. Along the first pCCA axis, lakes were evenly distributed. On the other side, taxa were clearly separated in two groups along first gradient, which implies the high effect of nutrients on littoral benthic invertebrates. Ammonium gradient was determined along the second axis of pCCA ordination diagram (20\% of variance explained). Lakes are evenly distributed along the ammonium gradient. Taxa were mostly distributed in the central part of the diagram along the second axis, indicating a weak relation to ammonium.

\subsubsection{Fish stocking gradient}

Only one gradient was determined from the fish stocking pCCA (Fig. 4d). The gradient along the first axis represents biomass of omnivorous fish, explaining 39\% of variance of benthic invertebrates. A majority of lakes and taxa were distributed in the central part along the omnivorous fish gradient. The centralized position of taxa implies that the omnivorous gradient fish had a weak effect on the littoral benthic invertebrates.

\subsubsection{Hydromorphological alteration gradients}

The hydromorphological alteration pCCA revealed two gradients (Fig. 4e). Along the first axis, littoral alteration gradient explained $27 \%$ of variance of littoral benthic 
R. Šiling and G. Urbanič : Knowl. Manag. Aquat. Ecosyst. 2016, 417, 35

Table 4. Marginal effects of environmental variables $\left(\lambda_{1}\right)$ including covariables, significance ( $p$-value) and group specific relative importance of each environmental variable (relative $\lambda_{1}$ ) for the littoral benthic invertebrate assemblage composition.

\begin{tabular}{|c|c|c|c|c|}
\hline Environmental variable & Variable group & $\lambda_{1}($ explained $\%)$ & Relative $\lambda_{1}$ & $p$-value \\
\hline Mean depth & Landscape characteristics & 16.2 & 1.0 & 0.001 \\
\hline Lake size & Landscape characteristics & 12.9 & 0.8 & 0.001 \\
\hline Altitude & Landscape characteristics & 12.4 & 0.8 & 0.001 \\
\hline Retention time & Landscape characteristics & 9.2 & 0.6 & 0.001 \\
\hline Catchment size & Landscape characteristics & 8.6 & 0.5 & 0.001 \\
\hline Intensive agriculture & Land use & 17.5 & 1.0 & 0.001 \\
\hline Extensive agriculture & Land use & 11.8 & 0.7 & 0.001 \\
\hline Urbanization & Land use & 10.2 & 0.6 & 0.002 \\
\hline Plantations & Land use & 7.7 & 0.4 & 0.003 \\
\hline Total phosphorous & Eutrophication & 15.4 & 1.0 & 0.001 \\
\hline Nitrate & Eutrophication & 9.5 & 0.6 & 0.001 \\
\hline Ammonium & Eutrophication & 9.1 & 0.6 & 0.002 \\
\hline Total nitrogen & Eutrophication & 7.8 & 0.5 & 0.003 \\
\hline Orthophosphate & Eutrophication & 7.5 & 0.5 & 0.005 \\
\hline Omnivorous & Fish stocking & 10.3 & 1.0 & 0.002 \\
\hline Herbi- and planktivorous & Fish stocking & 6.8 & 0.7 & 0.008 \\
\hline Invertivorous & Fish stocking & 5.7 & 0.6 & 0.055 \\
\hline Number of fish species & Fish stocking & 5.2 & 0.5 & 0.054 \\
\hline Piscivorous & Fish stocking & 4.8 & 0.5 & 0.097 \\
\hline Invertivorous-Piscivorous & & 2.4 & 0.2 & 0.829 \\
\hline Littoral zone & Hydromorphological alteration & 2.5 & 1.0 & 0.001 \\
\hline Lakeshore modification index & Hydromorphological alteration & 1.9 & 0.8 & 0.001 \\
\hline Lithal & Hydromorphological alteration & 1.9 & 0.8 & 0.002 \\
\hline Riparian zone & Hydromorphological alteration & 1.8 & 0.7 & 0.001 \\
\hline Xylal & Hydromorphological alteration & 1.6 & 0.6 & 0.005 \\
\hline Lakeshore zone & Hydromorphological alteration & 1.5 & 0.6 & 0.004 \\
\hline Fine substrate & Hydromorphological alteration & 1.3 & 0.5 & 0.025 \\
\hline Phytal & Hydromorphological alteration & 1.3 & 0.5 & 0.020 \\
\hline Argyllal & Hydromorphological alteration & 1.1 & 0.4 & 0.060 \\
\hline Particulate organic matter & & 1.0 & 0.4 & 0.198 \\
\hline
\end{tabular}

Variables that are not significant are italicized.

Table 5. Results of five partial CCAs. Analyses were conducted separately with fish stocking, land use, hydromorphological alteration and eutrophication variables with covariables. Groups of variables differ in spatial scale.

\begin{tabular}{|c|c|c|c|c|c|c|c|}
\hline Spatial scale & Group of variables & Covariables & $\begin{array}{l}\text { Total } \\
\text { inertia }\end{array}$ & $\begin{array}{l}\text { Eigenvalues } \\
\text { pCCA1 }\end{array}$ & $\begin{array}{l}\text { Eigenvalues } \\
\text { pCCA2 }\end{array}$ & $p$-value & $p^{*}$-value \\
\hline Catchment scale & Land use & Year & 1.636 & 0.31 & 0.17 & 0.001 & 0.001 \\
\hline Catchment scale/within lake & Landscape characteristics & Year & 1.636 & 0.31 & 0.14 & 0.001 & 0.001 \\
\hline Within lake & Eutrophication & Year & 1.636 & 0.26 & 0.11 & 0.001 & 0.001 \\
\hline Within lake & Fish stocking & Year & 1.636 & 0.19 & 0.12 & 0.014 & 0.002 \\
\hline On site & Hydromorphological alteration & Year, coordinates & 1.995 & 0.07 & 0.05 & 0.001 & 0.001 \\
\hline
\end{tabular}

Year-sampling year, coordinates - geographical coordinates, $p$-value-significance of first axis and $p^{*}$-value - significance for all axis.

invertebrates. Samples are concentrated on the right-hand side of the diagram, which represents highly hydromorphologically altered sites. On the left-hand side, where hydromorphological alteration is absent, we only have one site. Comparable variance was explained along the second axis $(17 \%)$, and reflected a substratum gradient along which sites and taxa were evenly distributed.

\subsection{Taxa along environmental gradients}

A partial CCA for separately tested groups of environmental variables suggested that there were two landscape gradients: one combination of landscape and stressor gradient, and six evident stressor gradients explaining the variance of littoral benthic invertebrates. Distribution of 


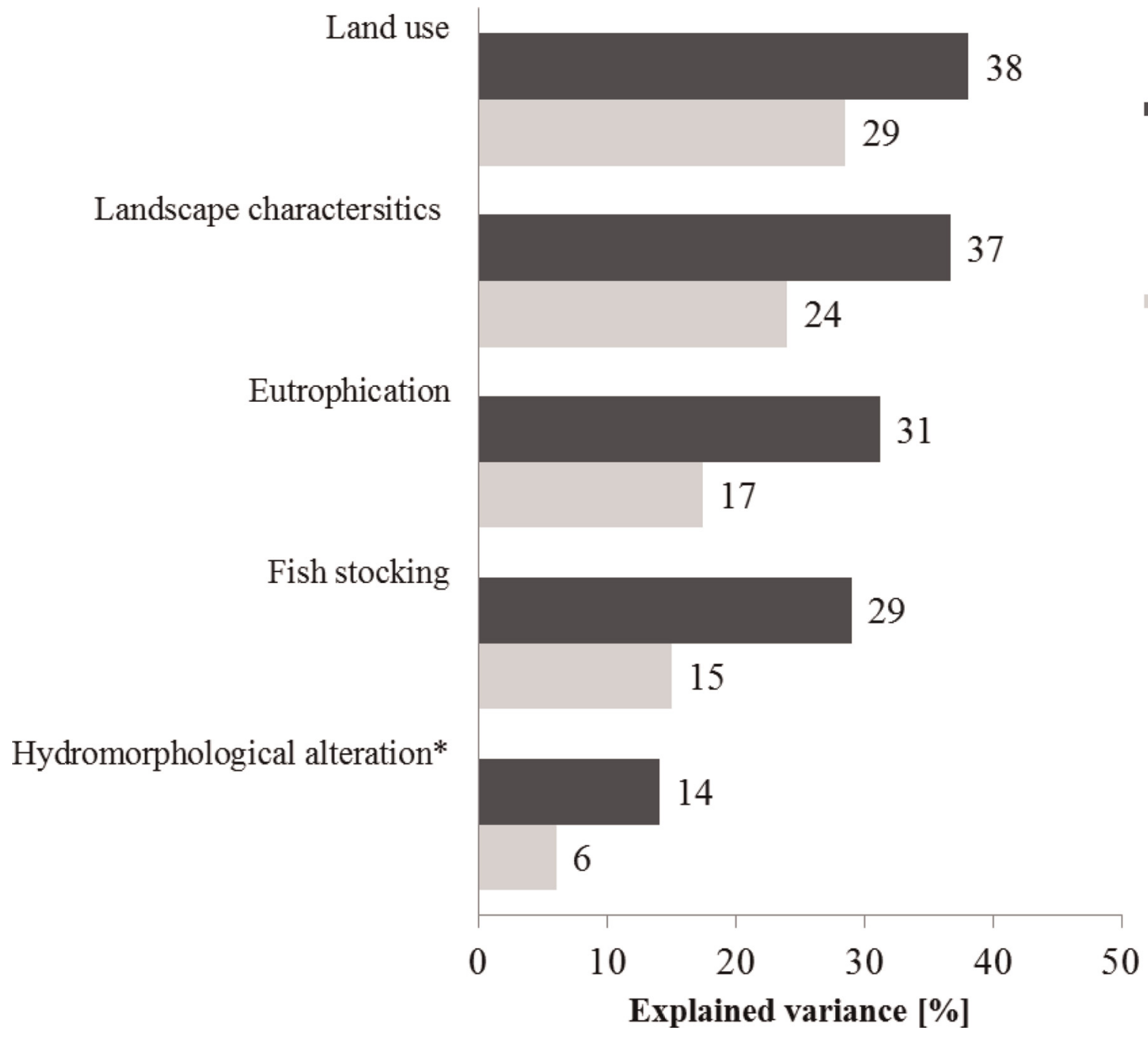

Fig. 3. Percentage of non-adjusted and adjusted explained variance in the littoral benthic invertebrate assemblages by each of the five groups individually.

benthic invertebrate taxa significantly differed in more than half of the gradients (Friedman test, $\chi^{2}(8)=196.929$; $p<0.0001$, Fig. 5). Pairwise analysis revealed significant differences in species scores between combinations of gradients $(Z=-1.508$ to $3.223 ; p<0.037$ to $<0.0001)$, which resulted in five established groups of gradients (Appendix 3; Fig. 5). The first group consisted of three gradients - lake morphometry, catchment size and urbanization. The second group was represented by urbanization and ammonium. The third group included ammonium, nutrients, intensive agriculture and littoral alteration. The fourth group included nutrients, intensive agriculture, littoral alteration and substratum. The distribution along gradient of omnivorous fish was unique and alone represented the fifth group. Besides observed differences in distribution of taxa, there was also a significant difference in sensitivity of taxa to landscape characteristics and stressors (Friedman test, $\chi^{2}(8)=292.686$; $p<0.0001$ ) (Appendix 3; Fig. 6). Significant differences occurred in few gradients pairs $(Z=0.789-1.603 ; p=0.043$ to $<0.0001)$ and resulted in four established groups of gradients (Appendix 3; Fig. 6). Higher sensitivity of taxa was detected in the first group, which consisted of lake morphometry, intensive agriculture, nutrients, omnivorous fish and urbanization. Intensive agriculture, nutrients, omnivorous fish, urbanization and catchment size formed a second group. The third group included nutrients, omnivorous fish, urbanization, catchment size, ammonium and littoral alteration. The fourth group was represented by ammonium, littoral alteration and substratum, and was characterized by taxa with higher tolerance values.

\section{Discussion}

This study has potential to support progress in indicator development, which at the moment is imperative for effective lake management. Identifying widely applicable bioindicators in multiple stressor environments will have a profound impact on management performances not only through separately assessing stressors' effects, but also through lowering the costs by defining hierarchy of actions, which prevent decline in ecological quality of lakes. 
R. Šiling and G. Urbanič : Knowl. Manag. Aquat. Ecosyst. 2016, 417, 35
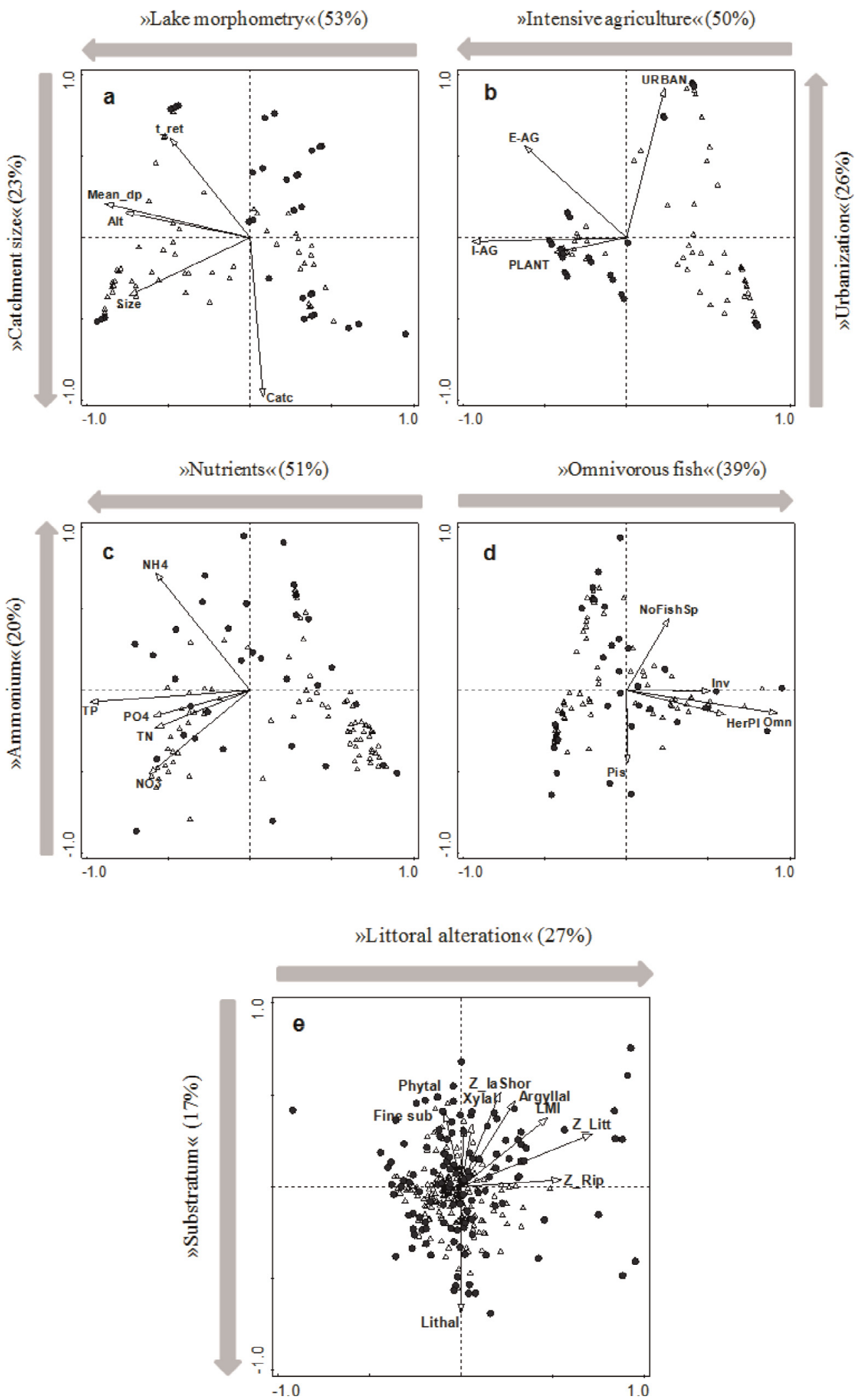

Fig. 4. Results of pCCA ordination (axes 1 and 2) of littoral invertebrate assemblages from 114 sampling sites and 32 lake-years. Next to the gradient explained fitted variation of axis is added. (a) Triplot of landscape characteristics, species and lake years. (b) Triplot of species, land use variables and lake years. (c) Triplot of species, lake-years and eutrophication variables. (d) Triplot of species, lake-years and fish stocking variables. (e) Triplot of species, sampling sites and hydromorphological variables. For abbreviations see Table 2 ( $\bullet-$ sampling sites or lake-years; $\Delta$-taxa). 


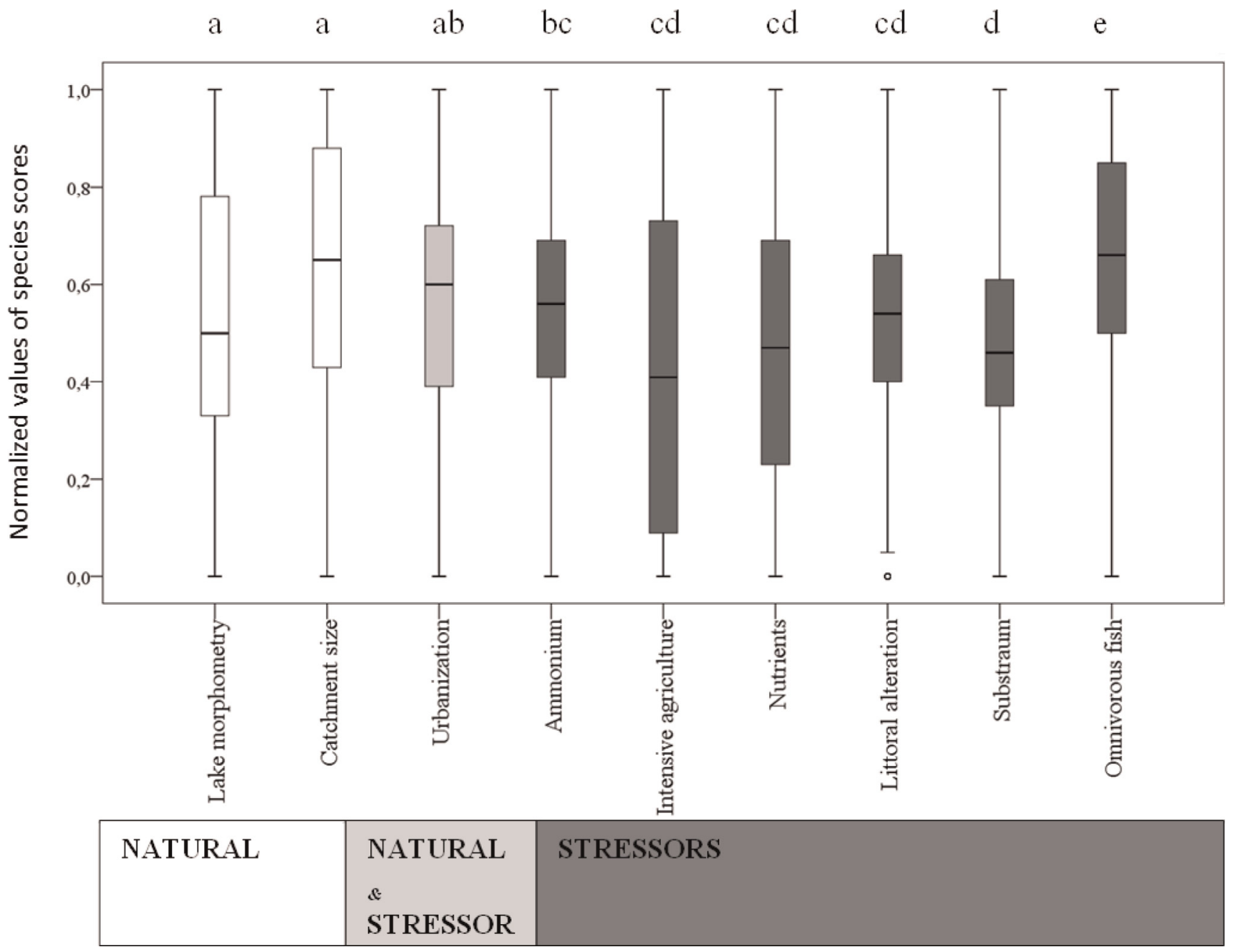

Fig. 5. Box plot showing the distribution of taxa based on normalized species scores along nine different gradients. Analysis is by Friedman test-letters indicate homogenous subgroups. The dark line inside each box represents the median; error bars show the minima and maxima except for outliers (open circles). The color of each box indicates the category of gradient along which littoral benthic invertebrates responded.

\subsection{Teasing apart drivers of littoral benthic assemblages}

Our sampling sites exhibit a wide range of chemical and physical factors, reflecting differences in landscape characteristics and anthropogenic disturbances among lakes and sampling sites. Environmental variables occur at different spatial scales-catchment zone (land use variables), catchment-within lake zone (landscape characteristics variables), within lake zone (eutrophication and fish stocking variables), riparian zone (hydromorphological alterations variables) and site zone (substrate variables). Comparison of stressors with lake-years units revealed that land use (29\%) and landscape characteristics $(24 \%)$ explained more variation in littoral benthic assemblage structure than eutrophication $(17 \%)$ and fish stocking (15\%). The pCCA results indicated a dominance of catchment scale variables over lower spatial scale variables, which corroborate the hypothesis of a hierarchical complexity of environmental factors (Poff, 1997). Johnson and Goedkoop (2002) also found this and argued that catchment variables define the upper limits for local factors representing closely cascading effects of environmental variables. Although in our case, we cannot directly compare explained variation of two different subsets (e.g., hydromorphological alteration vs eutrophication). Our results seemingly support the conclusion of Urbanič (2014b), indicating the possible dominance of eutrophication when assessing hydromorphological alterations of different lake types. In contrast to our findings, many researchers reported that local (morphological/habitat) variables dominate over within-lake variables (eutrophication) in shaping littoral benthic assemblages (Tolonen et al., 2001; McGoff and Sandin, 2012; Pilotto et al., 2015). The reason for discrepancy might be that in the mentioned studies temporal and spatial variability were not taken into consideration. Based on our results, it is evident that the factors at catchment and lake scale may be crucial for local littoral benthic invertebrate assemblage distribution. The latter also emphasizes the importance of using a hierarchical approach in management of lakes, especially when dealing with the effects of cooccurring environmental factors. Further, when assessing the effects of environmental factors, a prioritization of such factors at larger spatial scales is needed. However, since the distribution of littoral invertebrates is governed by the interplay of habitat structure, nutrient quantity and landscape 


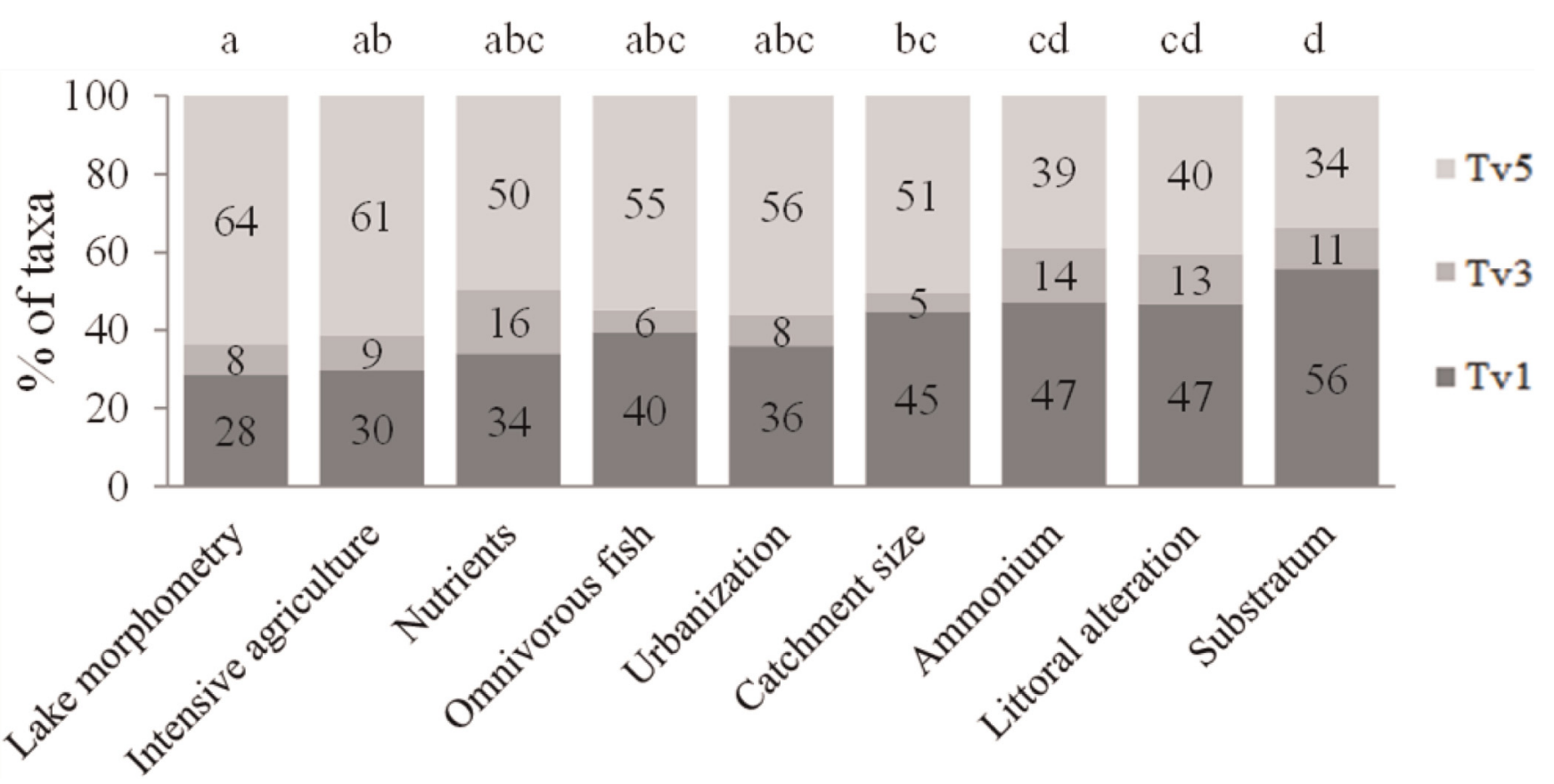

Fig. 6. Histogram showing the dispersion of taxa based on tolerance values grouped in ranges along nine different gradients. Analysis is by Friedman test-letters indicate homogenous subgroup.

characteristics, one should acknowledge factors on numerous spatial scales.

Comparison of littoral benthic invertebrates' responses with multiple environmental gradients simplifies mechanisms explaining relationships between different environmental factors and littoral benthic assemblage. As the structure of assemblages is a reflection of the on-site conditions and the influences of the catchment conditions, which are expressed directly and indirectly, responses along some gradients are not independent. According to previous studies (Brodersen et al., 1998; Stefanidis and Papastergiadou, 2012; Mehner et al., 2007), the morphology of lakes is one of the most important factors controlling the trophic status, physico-chemistry, productivity and distribution of aquatic organisms. This was supported in our study, where littoral benthic invertebrates tended to be gradually distributed along a lake morphometry gradient. Lake mean depth explained the highest variance of littoral benthic assemblages, which supports previous findings of mean depth as a key predictor for benthic invertebrates (Brodersen et al., 1998). A possible explanation lies in differences of nutrient mixing, thermal stratification and usually vegetation cover (Wetzel, 2001), all of which are linked to food availability and habitat quality. The same explicit interpretation cannot be made for the catchment size gradient. We did not find any study revealing the direct impact of catchment size on littoral benthic assemblages. However, the influence of the catchment size effects should be greater when the catchment is larger and impaired. Hence, many researchers focus rather on the effects of land use in catchment on assemblages. Generally, land use depends on suitability of the area for urban and agricultural development (Petek, 2004). Thus, coinciding responses along urbanization gradient and gradients within landscape characteristics variables were expected. Urbanization and intensive agriculture seems to be related to ammonium as the commonest sources of ammonium are sewage effluents and effluents associated with industries producing coals, gas, coke and fertilizers (Hall et al., 1999; Wang et al., 2006). Usually the effect of ammonium is interpreted through the depletion of oxygen (Rosenberg and Schleifer, 2006) or a toxic effect (Camargo et al., 2005), which influences littoral benthic assemblage structure (Verdonschot and Verdonschot, 2014). Pattern of responses along intensive agriculture, nutrients, littoral alteration and substratum gradient, where no differences were recognized, could be interpreted through a few mechanisms. Effects of intensive agriculture on littoral benthic assemblages are indirect, such as habitat destruction and nutrient loading, which leads to eutrophication processes (e.g., Fraterrigo and Downing, 2008; Kovalenko et al., 2010). Consequently, the responses of littoral benthic invertebrates to nutrients are partially integrated in responses to agricultural land use. Furthermore, nutrient enrichment promotes the changes in habitat structure (Donohue et al., 2009a). More specifically, this indicates that nutrients are surrogates for increased allochthonous material (litter fall), which affect substratum composition. Substratum is also strongly related to hydromorphological changes (McGoff et al., 2013; Peterlin and Urbanič, 2013; Urbanič, 2014b), more precisely to littoral alteration, which causes direct impacts on littoral benthic assemblages (Johnson and Goedkoop, 2002; Porst et al., 2016).

Benthic invertebrates' responses along an omnivorous fish gradient, which show distinction among gradients, are not so evident. Independent responses of littoral benthic invertebrates along an omnivorous fish gradient should serve as a reminder for taking a holistic approach, especially while assessing the impact of stressors, and highlight underestimation of some stressors' effects. We assume that the differences in responses along the omnivorous fish gradient reflect the ubiquitousness 
of the fish stocking stressor, which is independent from natural lake characteristics and other alterations. Although several researchers focused on the impact of biomanipulation in lakes (e.g., Eby et al., 2006), our knowledge on the effects of fish stocking on littoral benthic assemblages in different types of lakes is scarce. Presence of fish can influence littoral benthic invertebrates in several ways, including biological interactions, nutrient dynamics, sedimentation, and oxygen dynamics (Brönmark and Hansson, 2005; Bernes et al., 2013). Despite the short length of our fish stocking gradient $(0-1000 \mathrm{~kg} / \mathrm{ha})$ compared with other studies, importance of fish stocking was supported by our findings (e.g., Berg et al., 1997; Nasmith et al., 2010). Nonetheless, the second unrecognisable gradient may point out the unavailability of detailed predictors data like fish population density of each lake.

Some processes still make separation of littoral benthic assemblages' responses among gradients difficult. However, five groups of gradients represented responsiveness along three categories of gradients: from natural through mixture of natural and stressors over to stressor gradients. Despite the fact that correlations among stressors might be present, independent responsiveness provides good evidence about applicability of littoral benthic invertebrates as a bioindicator tool. As a bioindicator, they can help identify stressors reflecting urbanization (masking the effect of ammonium), stocking of omnivorous fish and eutrophication, which might be caused by intensive agriculture or littoral alteration which affects the regrowth of primary producers (e.g., macrophytes) and contributes to primary production. Taxa also showed different responses to littoral alteration and substratum gradients, independent from activities in catchment, implying that morphological changes might be identified separately. Taken together, littoral benthic invertebrates show potential in disentangling multiple stressors, which would likely solve one of the key issues in freshwater management.

\subsection{Bioindication}

Benthic invertebrates have a long history of use in bioassessment due to their sensitivity to different environmental changes (Furse et al., 2006). Based on three tolerance groups of taxa, our analysis revealed preeminence of specialists on generalists along six gradients. Specialists are the most useful environmental indicator species, due to the preference for certain relatively narrow environmental conditions (Soininen, 2007). Hence, our results imply that benthic invertebrates could be good indicators for gradients along natural characteristics of lakes, intensive agriculture, omnivorous fish, urbanization and nutrient concentrations. The tolerance structure of benthic invertebrate taxa along substratum gradient exhibited a surprisingly bigger share of generalists, which is contrary to many studies, which show relatedness of invertebrates to substratum type (e.g., Pilotto et al., 2015). One possible reason for divergence in conclusions may be different sampling technique. While we used a proportional stratified sampling approach, others used habitat specific sampling. Moreover, the dominance of generalists was found also along ammonium, littoral alteration and substratum gradients, consistently supporting the assumption about dominance of large scale stressor effects over small scale stressor effects (Urbanič, 2014b). However, one has to consider that lentic invertebrates have developed a wide array of adaptations in order to cope with changes in environment, resulting in significant tolerance values (Sharitz and Batzer, 1999). Due to the long term of anthropogenic alteration, shifts have happened in assemblage composition, resulting in species adapted to low stressor (e.g., nutrient) environments being replaced by stress tolerant species.

Sensitivity of taxa to varying stressors serves as the basis for index development for use in assessing quality of lakes. Considering one to three taxon characteristics (indicative value, indicative weight based on tolerance values and abundance), robust indices might be developed (Saprobien index, Zelinka and Marvan, 1961; Urbanič, 2014a). According to our results, a bigger share of specialists than generalists along the majority of gradients should encourage the use of littoral benthic invertebrates in lake bioassessment.

\section{Conclusions}

In order to enhance lake status while dealing with multiple stressors, managers strive to use bioindicators that can respond to various stressors and identify the hierarchical structure of environmental factors. We recognized that the order of natural and anthropogenic factors indicates that catchment-scale factors should take precedence over local scale factors when anthropogenic interventions are necessary to improve ecological conditions of lakes. Differences in responses along nine environmental gradients indicate that littoral benthic invertebrates can be used to independently assess the impact of varied stressors (hydromorphological alterations, fish stocking, eutrophication and urbanization), and thus fulfill the requirements for the effective stressor-specific biotic indices. Occurrence of relatively high numbers of sensitive taxa along gradients implies that the key stressors can be assessed using a taxonomical composition of littoral benthic invertebrates. There is no similar study, to our knowledge, based on a diverse data set from lowland lakes to alpine lakes, which simultaneously considers spatial and temporal variability. Hence, our findings have practical implications for ecological assessment and effective management of lakes, as they indicate that benthic invertebrates can be used when the effects of multiple stressors need to be disentangled. We advocate development of varied littoral benthic invertebrate based stressor-specific indices in order to maximize cost-effectiveness of lake management.

Conflict of interest. The authors declare that they have no conflict of interest.

Acknowledgments. This study was supported by the Slovenian Research Agency (Contract No. 1000-15-0211) and Ministry of the Environment and Spatial Planning of the Republic of Slovenia. We would like to thank Samo Podgornik who provided fish stocking data and Environment Agency of Slovenia for providing eutrophication data. We would also like to thank Marc Schallenberg and Vesna Petkovska for useful comments to a previous version of the manuscript. The authors gratefully acknowledge Thomas Horvath for his valuable comments and for correcting the English. 


\section{R. Šiling and G. Urbanič : Knowl. Manag. Aquat. Ecosyst. 2016, 417, 35}

\section{References}

Allan J. 2004. Influence of land use and landscape setting on the ecological status of rivers. Limnetica 23: 187-198.

AQEM consortium. 2002. Manual for the application of the AQEM method. A comprehensive method to assess European streams using benthic macroinvertebrates, developed for the purpose of the Water Framework Directive. Version 1.0, February 2002. Contract No. EVK1-C T1999-00027.

Bazzanti M, Mastrantuono L, Solimini AG. 2012. Selecting macroinvertebrate taxa and metrics to assess eutrophication in different depth zones of Mediterranean lakes. Fundam Appl Limnol/Arch Hydrobiol 180: 133-143.

Berg S, Jeppesen E, Sondergaard M. 1997. Pike (Esox lucius L) stocking as a biomanipulation tool: 1. Effects on the fish population in Lake Lyng, Denmark. Hydrobiologia 342: 311318.

Bernes C, Carpenter SR, Gardmark A. et al. 2013. What is the influence on water quality in temperate eutrophic lakes of a reduction of planktivorous and benthivorous fish? A systematic review protocol. Environ Evid 2: 9.

Borisko JP, Kilgour BW, Stanfield LW, Jones FC. 2007. An evaluation of rapid bioassessment protocols for stream benthic invertebrates in Southern Ontario, Canada. Water Qual Res J Can 42: 184-193.

Bozelli RL, Caliman A, Guariento RD, et al. 2009. Interactive effects of environmental variability and human impacts on the long-term dynamics of an Amazonian floodplain lake and a South Atlantic coastal lagoon. Limnologica 39: 306-313.

Brodersen KP, Dall PC, Lindegaard C. 1998. The fauna in the upper stony littoral of Danish lakes: macroinvertebrates as trophic indicators. Freshw Biol 39: 577-592.

Brönmark C, Hansson LA. 2005. The biology of lakes and ponds, 2nd ed. Oxford: Oxford University Press, 285 p.

Camargo JA, Alonso A, Salamanca A. 2005. Nitrate toxicity to aquatic animals: a review with new data for freshwater invertebrates. Chemosphere 58: 1255-1267.

Corine Land Cover. 2006. Eionet. European Topic Centre for Spatial information and Analysis. http://sia.eionet.europa.eu/CLC2006 (accessed 25.02.13).

Crain CM, Kroeker K, Halpern BS. 2008. Interactive and cumulative effects of multiple human stressors in marine systems. Ecol Lett 11: 1304-1315.

Donohue I, Irvine K. 2003. Effects of sediment particle size composition on survivorship of benthic invertebrates from Lake Tanganyika, Africa. Arch Hydrobiol 157: 131-144.

Donohue I, Donohue LA, Ainín BN, Irvine K. 2009a. Assessment of eutrophication pressure on lakes using littoral invertebrates. Hydrobiologia 633: 105-122.

Donohue I, Jackson AL, Pusch M, Irvine K. 2009b. Nutrient enrichment homogenizes lake benthic assemblages at local and regional scales. Ecology 90: 3470-3477.

Dußling U, Berg R, Klinger H, Wolter C. 2004. Assessing the Ecological Status of River Systems Using Fish Assemblages. Handbuch Angewandte Limnologie 20. Erg.Lfg. 12, 84 p.

Eby LA, Roach WJ, Crowder LB, Stanford JA. 2006. Effects of stocking-up freshwater food webs. Trends Ecol Evol 21: $576-584$.

EPA. 2006. Estimation and Application of Macroinvertebrate Tolerance Values. Washington, DC 20460: National Center for Environmental Assessment Office of Research and Development U.S. Environmental Protection Agency.
European Union. 2000. Directive 2000/60/EC of the European Parliament and of the Council of October 2000 establishing a framework for Communities in the field of water policy, Official Journal of the European Communities, L 327/1, 22.12.2000.

Fraterrigo JM, Downing JA. 2008. The influence of land use on lake nutrients varies with watershed transport capacity. Ecosystems 11: 1021-1034.

Friberg N. 2014. Impacts and indicators of change in lotic ecosystems. Wiley Interdiscip Rev Water. Doi:10.1002/wat2.1040.

Furse MT, Hering D, Brabec K, Buffagni A, Sandin L, Verdonschot P. 2006. The ecological status of European rivers: evaluation and intercalibration of assessment methods. Hydrobiologia 566: $1-2$.

Gabel F, Garcia XF, Schnauder I, Pusch MT. 2012. Effects of shipinduced waves on littoral benthic invertebrates. Freshw Biol 57: $2425-2435$

Hall RI, Leavitt PR, Quinlan R, Dixit AS, Smol JP. 1999. Effects of agriculture, urbanization, and climate on water quality in the northern Great Plains. Limnol Oceanogr 44: 739-756.

Hanson MA, Herwig BR, Zimmer KD, et al. 2012. Comparing effects of lake- and watershed-scale influences on communities of aquatic invertebrates in shallow lakes. PLOS ONE 7: 9.

IBM. 2012. IBM SPSS Statistics 21 Core System User's Guide. Armonk: IBM Corporation, 1989, 2012.

Jenkins M. 2003. Prospects for biodiversity. Science 302: 1175-1177.

Johnson RK, Goedkoop W. 2002. Littoral macroinvertebrate communities: spatial scale and ecological relationships. Freshw Biol 47: 1840-1854.

Johnson RK, Hering D, Furse MT, Clarke RT. 2006. Detection of ecological change using multiple organism groups: metrics and uncertainty. Hydrobiologia 566: 115-137.

Johnson RK, Hering D. 2009. Response of taxonomic groups in streams to gradients in resource and habitat characteristics. $J$ Appl Ecol 46: 175-186.

Jurca T, Donohue L, Laketić D, Radulović S, Irvine K. 2012. Importance of the shoreline diversity features for littoral macroinvertebrate assemblages. Fundam Appl Limnol/Arch Hydrobiol 180: 175-184.

Jyväsjärvi J, Aroviita J, Hämäläinen H. 2011. Evaluation of approaches for measuring taxonomic completeness of lake profundal macroinvertebrate assemblages. Freshw Biol 56: 1876$-1892$.

Jyväsjärvi J, Aroviita J, Hämäläinen H. 2012. Performance of profundal macroinvertebrate assessment in boreal lakes depends on lake depth. Fundam Appl Limnol/Arch Hydrobiol 180: 91-100.

Kovalenko KE, Brady VJ, Brown TN, et al. 2010. Congruence of community thresholds in response to anthropogenic stress in Great Lakes coastal wetlands. Freshw Sci 33: 958-971.

Leppä M, Hämäläinen H, Karjalainen J. 2003. The response of benthic macroinvertebrates to whole-lake biomanipulation. Hydrobiologia 498: 97-105.

Li L, Zheng B, Liu L. 2010. Biomonitoring and bioindicators used for river ecosystems: definitions, approaches and trends. Proc Environ Sci 2: $1510-1524$.

Longing SD, Voshell JR, Dolloff CA, Roghair CN. 2010. Relationships of sedimentation and benthic macroinvertebrate assemblages in headwater streams using systematic longitudinal sampling at the reach scale. Environ Monit Assess 161: 517-530.

Mazzoni AC, Lanzer R, Schafer A. 2014. Tolerance of benthic macroinvertebrates to organic enrichment in highland streams of northeastern Rio Grande do Sul, Brazil. Acta Limnol Bras 26: $119-128$. 
McGoff E, Sandin L. 2012. Catchment land-use effects on littoral macroinvertebrates in response to local habitat structure and trophic state. Fundam Appl Limnol/Arch Hydrobiol 180: 111121.

McGoff E, Aroviita J, Pilotto F, et al. 2013. Assessing the relationship between the Lake Habitat Survey and littoral macroinvertebrate communities in European lakes. Ecol Indic 25: 205-214.

Mehner T, Holmgren K, Lauridsen TL, Jeppesen E, Diekmann M. 2007. Lake depth and geographical position modify lake fish assemblages of the European "Central Plains" ecoregion. Freshw Biol 52: 2285-2297.

Miler O, Porst G, Mcgoff E, et al. 2014. An index of human alteration of lake shore morphology. Aquat Conserv Mar Freshw Ecosyst 25: 353-364.

Monroe JB, Baxter CV, Olden JD, Angermeier PL. 2009. Freshwaters in the public eye: understanding the role of images and media in aquatic conservation. Fisheries 34: 581-585.

Nasmith LE, Tonn WM, Paszkowski CA, Scrimgeour GJ. 2010. Effects of stocked trout on native fish communities in boreal foothills lakes. Ecol Freshw Fish 19: 279-289.

Nõges T. 2009. Relationships between morphometry, geographic location and water quality parameters of European lakes. Hydrobiologia 633: 33-43.

O'Toole C, Donohue I, Moe SJ, Irvine K. 2008. Nutrient optima and tolerances of benthic invertebrates, the effects of taxonomic resolution and testing of selected metrics in lakes using an extensive European data base. Aquat Ecol 42: 277-291.

OGRS. 2009. Rules on monitoring of surface water. Pravilnik o monitoringu stanja površinskih voda. Official Gazette of the Republic of Slovenia 10: 832-839 (in Slovene) http://www.uradnilist.si/_pdf/2009/Ur/u2009010.pdf (accessed 02.02.16).

Pavlin M, Birk S, Hering D, Urbanič G. 2011. The role of land use, nutrients, and other stressors in shaping benthic invertebrate assemblages in Slovenian rivers. Hydrobiologia 678: 137-153.

Petek F. 2004. Land use in Slovenia, Slovenia: a geographical overview, ZRC SAZU, Ljubljana 105-108. http://zgs.zrc-sazu.si/ Portals/8/Slo_Geo_Over/19.pdf (accessed 02.02.16).

Peterlin M, Urbanič G. 2013. A Lakeshore Modification Index and its association with benthic invertebrates in alpine lakes. Ecohydrology 6: 297-311.

Petkovska V, Urbanič G. 2015. The links between morphological parameters and benthic invertebrate assemblages, and general implications for hydromorphological river management. Ecohydrology 8: 67-82.

Pierce CL, Hinrichs BD. 1997. Response of littoral invertebrates to reduction of fish density: simultaneous experiments in ponds with different fish assemblages. Freshw Biol 37: 397408.

Pilotto F, Bazzanti M, Di Vito V, et al. 2015. Relative impacts of morphological alteration to shorelines and eutrophication on littoral macroinvertebrates in Mediterranean lakes. Freshw Sci 34: 410-422.

Poff NL. 1997. Landscape filters and species traits: towards mechanistic understanding and prediction in stream ecology. J North Am Benthol Soc 16: 391-409.

Porst G, Miler O, Donohue L, et al. 2016. Efficient sampling methodologies for lake littoral invertebrates in compliance with the European Water Framework Directive. Hydrobiologia 767: 207-220.

R Development Core Team. 2011. R: A Language and Environment for Statistical Computing. Vienna, Austria: R Foundation for Statistical Computing. http://www.R-project.org (accessed 02.02.16).
Remec Rekar Š. 2009. Lake water quality monitoring in Slovenia report. Ljubljana, Slovenia: Environmental Agency of the Republic of Slovenia, 35 p. (in Slovene). Available at http://www.arso.gov.si/ vode/jezera/PORORO \%C4\%8CILO\%20JEZERA\%202009_splet. pdf

Rosenberg E, Schleifer KH. 2006. The prokaryotes: Vol. 2: Ecophysiology and Biochemistry, 3rd ed., New York: Springer, $1107 \mathrm{p}$.

Sandin L, Johnson RK. 2000. The statistical power of selected indicator metrics using macroinvertebrates for assessing acidification and eutrophication of running waters. Hydrobiologia 422: 233-243.

Sandin L, Solimini AG. 2009. Freshwater ecosystem structurefunction relationships: from theory to application. Freshw Biol 54: 2017-2024

Schinegger R, Trautwein C, Melcher A, Schmutz S. 2012. Multiple human pressures and their spatial patterns in European running waters. Water Environ J 26: 261-273.

Sharitz R, Batzer D. 1999. An introduction to freshwater wetlands in North America and their invertebrate fauna. In: Batzer DP, Rader $\mathrm{RB}$, Wissinger SA, eds. Invertebrates in freshwater wetlands of North America: ecology and management. New York: Wiley, pp. 1-22.

Soininen J. 2007. Environmental and spatial control of freshwater diatoms - a review. Diatom Res 22: 473-490.

Solimini AG, Free G, Donohue I, et al. 2006. Using Benthic Macroinvertebrates to Assess Ecological Status of Lakes Current Knowledge and Way Forward to Support WFD Implementation. Environment EUR 22347, 48.

Stefanidis K, Papastergiadou E. 2012. Relationships between lake morphometry, water quality, and aquatic macrophytes, in Greek lakes. Fresenius Environ Bull 21: 3018-3026.

Stendera S, Adrian R, Bonada N, et al. 2012. Drivers and stressors of freshwater biodiversity patterns across different ecosystems and scales: a review. Hydrobiologia 696: 1-28.

Ter Braak CJF, Šmilauer P. 2012. Canoco Reference Manual and User's Guide: Software for Ordination, Version 5.0. Ithaca, USA: Microcomputer Power, $496 \mathrm{p}$.

Tolonen KT, Hamalainen H, Holopainen IJ, Karjalainen J. 2001. Influences of habitat type and environmental variables on littoral macroinvertebrate communities in a large lake system. Arch Hydrobiol 152: 39-67.

Urbanič G. 2014a. Hydromorphological degradation impact on benthic invertebrates in large rivers in Slovenia. Hydrobiologia 729: 191-207.

Urbanič G. 2014b. A Littoral Fauna Index for assessing the impact of lakeshore alterations in Alpine lakes. Ecohydrology 7: 703-716.

Urbanič G, Petkovska V, Pavlin M. 2012. The relationship between littoral benthic invertebrates and lakeshore modification pressure in two alpine lakes. Fundam Appl Limnol/Arch Hydrobiol 180: $157-173$.

Urbanič G, Mohorko T, Peterlin M, et al. 2013. Decree on surface water status: expert groundwork. Ljubljana: Institute for Water of the Republic of Slovenia, 63 p. (in Slovene).

Vadeboncoeur Y, Lodge DM, Carpenter SR. 2001. Whole-lake fertilization effects on distribution of primary production between benthic and pelagic habitats. Ecology 82: 1065-1077.

Verdonschot PFM, Spears BM, Feld CK, et al. 2013. A comparative review of recovery processes in rivers, lakes, estuarine and coastal waters. Hydrobiologia 704: 453-474.

Verdonschot RCM, Verdonschot PFM. 2014. Shading effects of freefloating plants on drainage-ditch invertebrates. Limnology 15: 225-235. 
R. Šiling and G. Urbanič : Knowl. Manag. Aquat. Ecosyst. 2016, 417, 35

Walker I. 1998. Population dynamics of Chironomidae (Diptera) in the central Amazon blackwater river Tarumã-Mirim (Amazonas, Brazil). Oecologia Brasiliensis 5: 235-252.

Wang L, Seelbach P, Hughes R. 2006. Introduction to landscape influences on stream habitats and biological assemblages. Landsc Influ Stream Habitat Biol Assem 48: 1-23.

Wetzel RG. 2001. Limnology: lake and river ecosystems, 3rd ed., San Diego: Academic Press, 1006 p.

White J, Irvine K. 2003. The use of littoral mesohabitats and their macroinvertebrate assemblages in the ecological assessment of lakes. Aquat Conserv Mar Freshw Ecosyst 13: $331-351$.
Williams D. 1996. Environmental constraints in temporary fresh waters and their consequences for the insect fauna. $J$ North Am Benthol Soc 15: 634-650.

Yuan LL. 2004. Assigning macroinvertebrate tolerance classifications using generalised additive models. Freshw Biol 49: 662-677.

Zelinka M, Marvan P. 1961. Zur Präzisierung der biologischen Klassifikation der Reinheit fließender Gewässer. Arch Hydrobiol 57: 389-407.

Zohary T, Ostrovsky I. 2011. Ecological impacts of excessive water level fluctuations in stratified freshwater lakes. Inl Waters 1: 47-59.

Zuur AF, Ieno EN, Elphick CS. 2010. A protocol for data exploration to avoid common statistical problems. Methods Ecol Evol 1: 3-14.

Cite this article as: Šiling R, Urbanič G. 2016. Do lake littoral benthic invertebrates respond differently to eutrophication, hydromorphological alteration, land use and fish stocking? Knowl. Manag. Aquat. Ecosyst., 417, 35. 
R. Šiling and G. Urbanič : Knowl. Manag. Aquat. Ecosyst. 2016, 417, 35

\section{Appendix 1}

Spearman's rank correlation coefficients between environmental variables within each group.

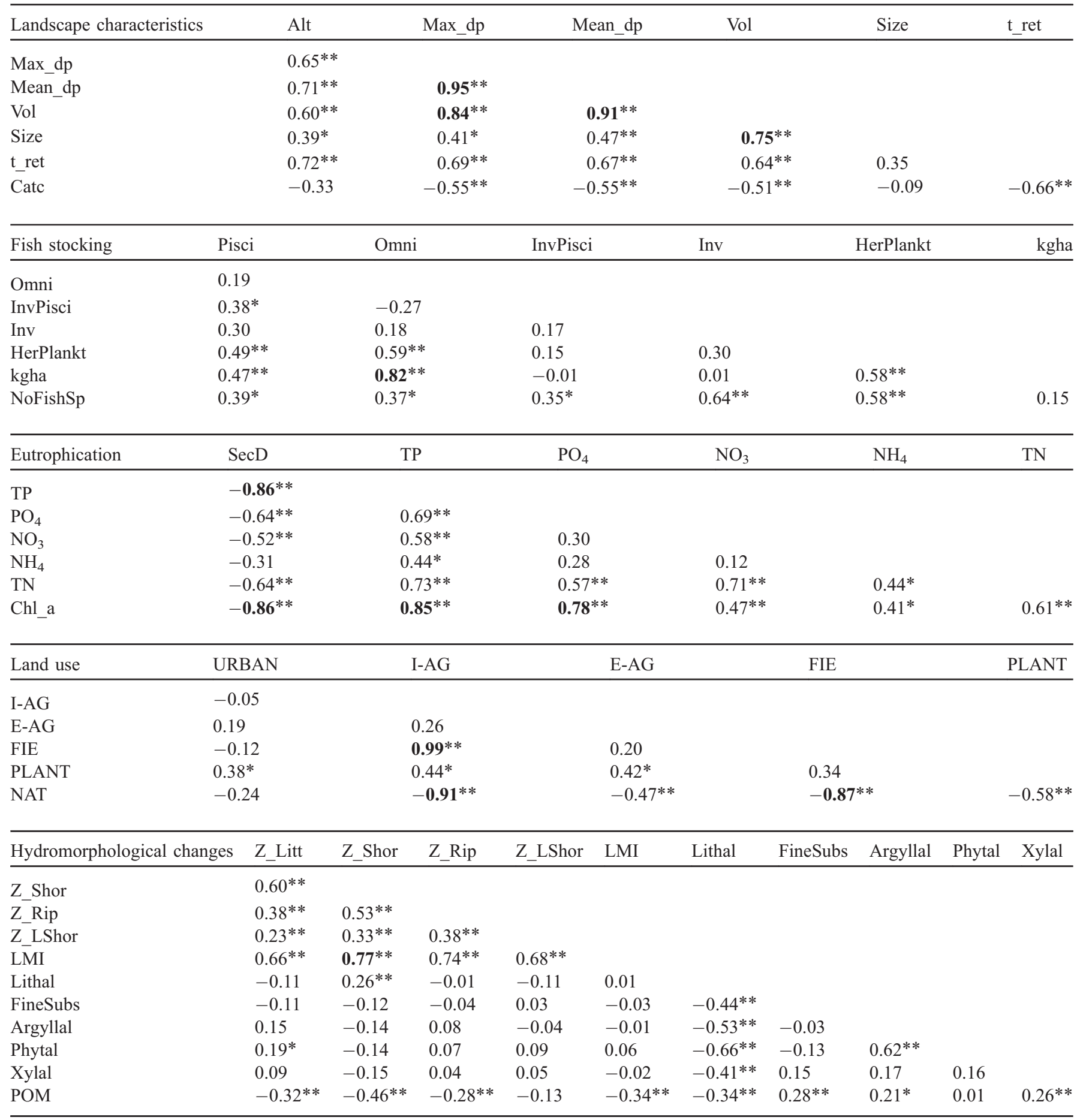

Significance is shown as asterisks $\left(* * *: p<0.001,{ }^{* *}: p<0.01, *: p<0.05\right)$. Bold values are strong correlations $(\mathrm{Rs}>0.75)$. For environmental variable codes see Table 2. 
R. Šiling and G. Urbanič : Knowl. Manag. Aquat. Ecosyst. 2016, 417, 35

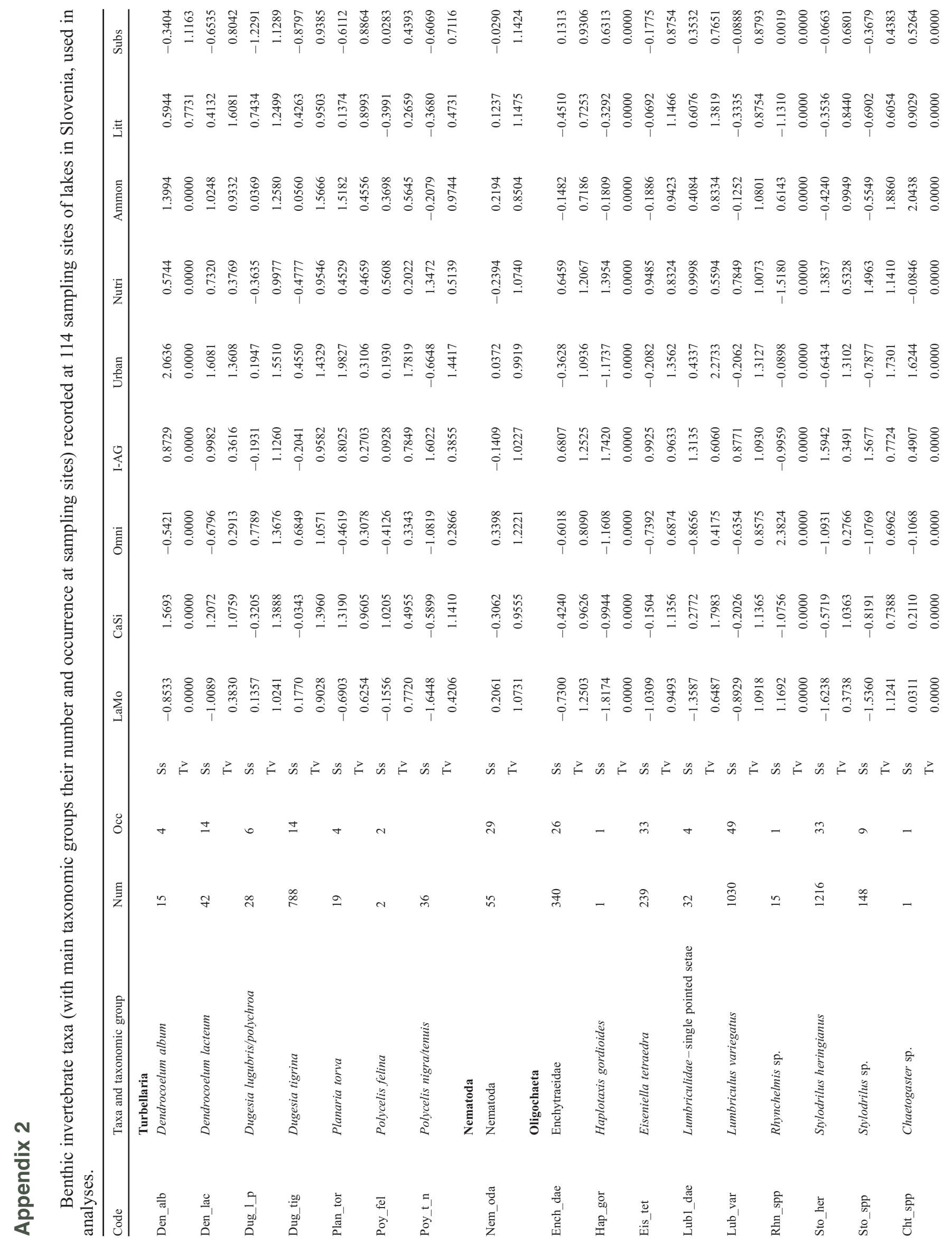


R. Šiling and G. Urbanič : Knowl. Manag. Aquat. Ecosyst. 2016, 417, 35

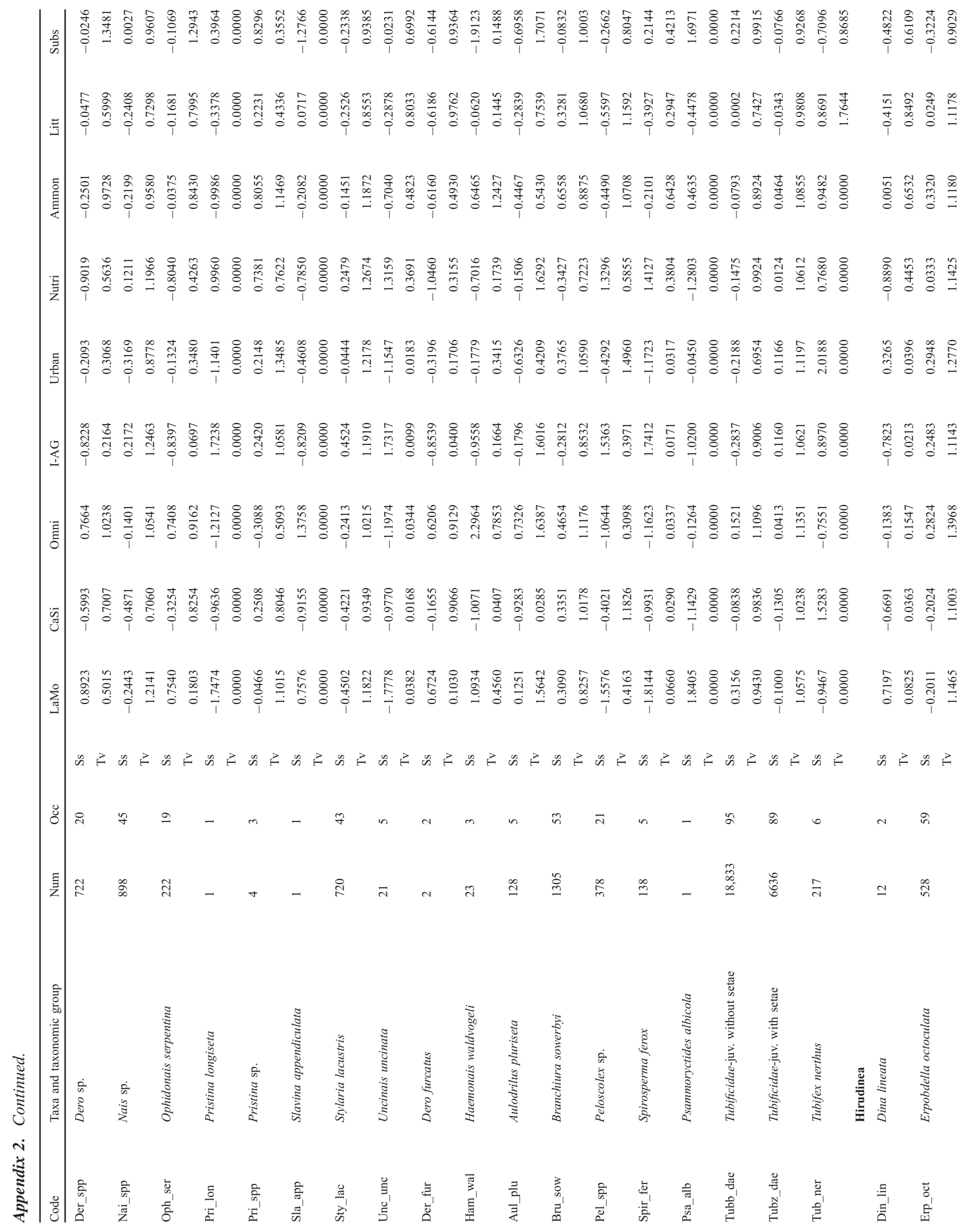


R. Šiling and G. Urbanič : Knowl. Manag. Aquat. Ecosyst. 2016, 417, 35

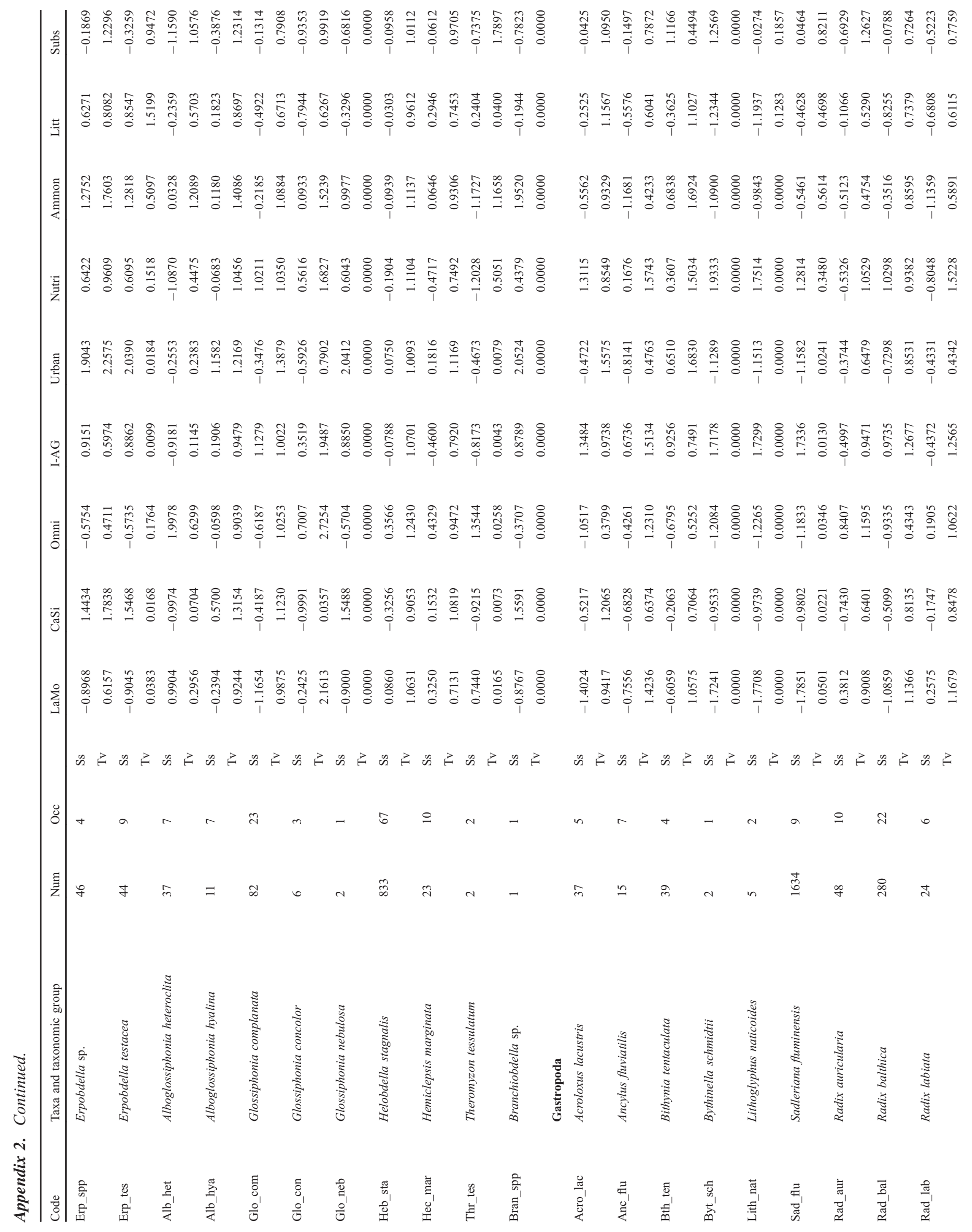


R. Šiling and G. Urbanič : Knowl. Manag. Aquat. Ecosyst. 2016, 417, 35
产

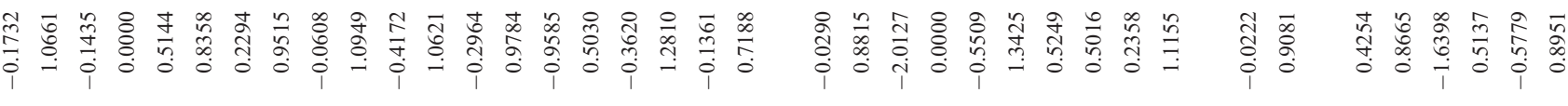

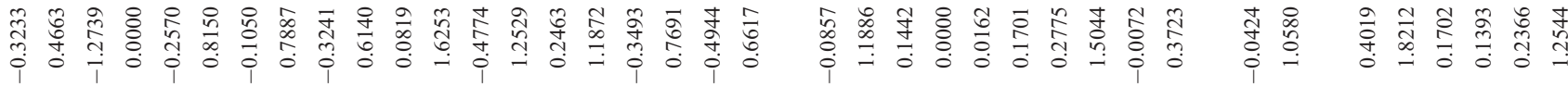

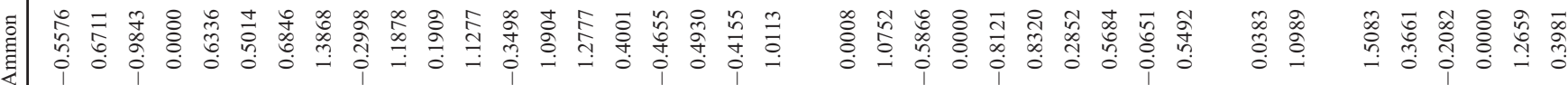

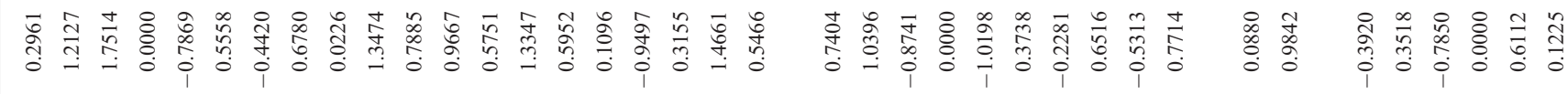

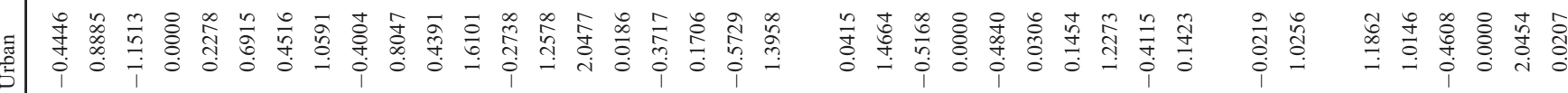

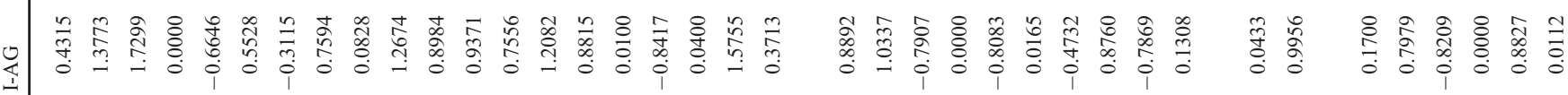

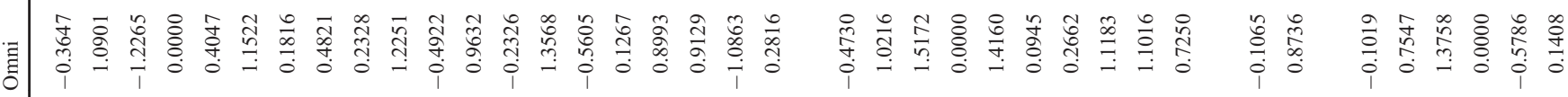

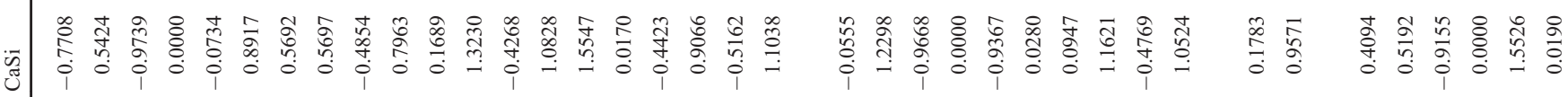

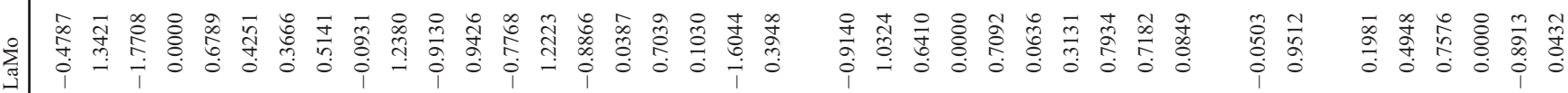

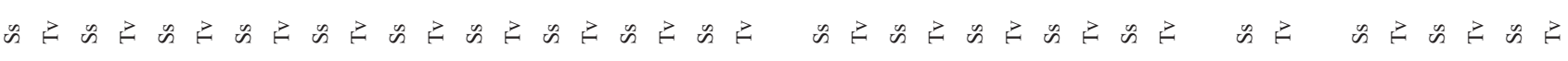

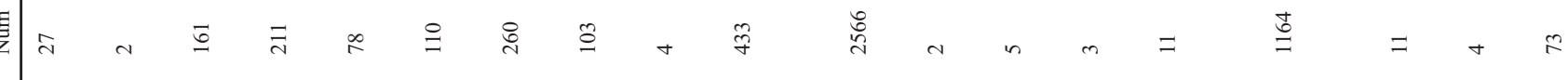

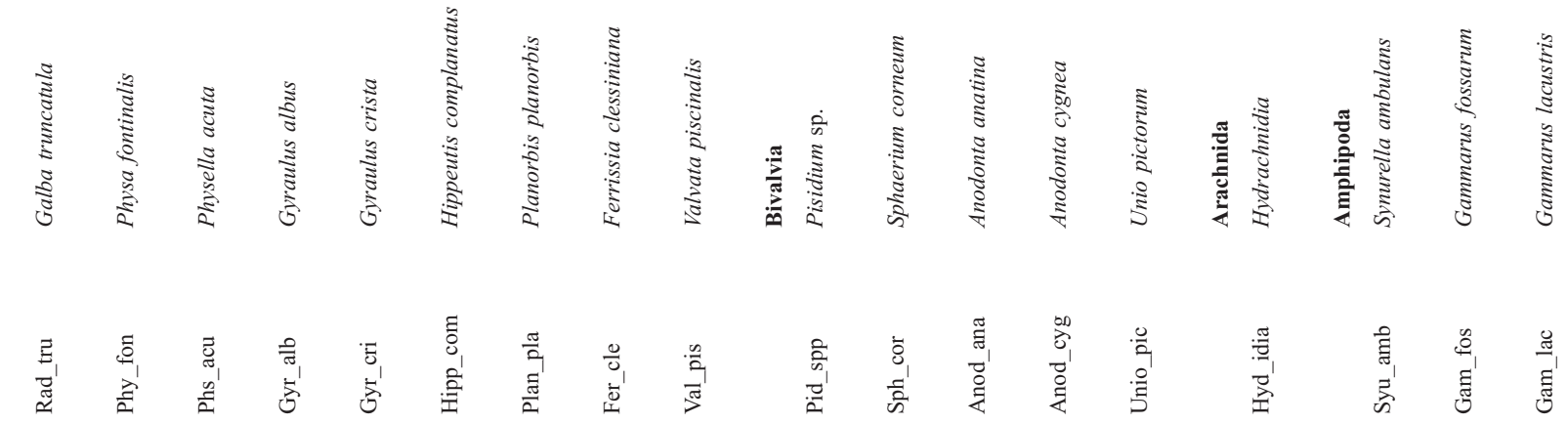


R. Šiling and G. Urbanič : Knowl. Manag. Aquat. Ecosyst. 2016, 417, 35

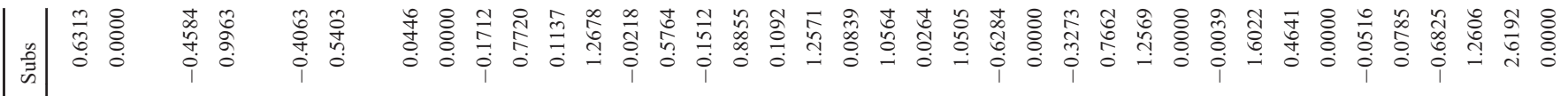

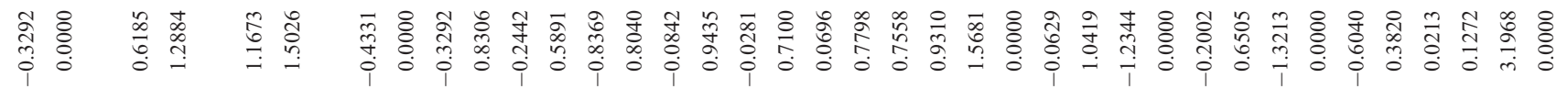

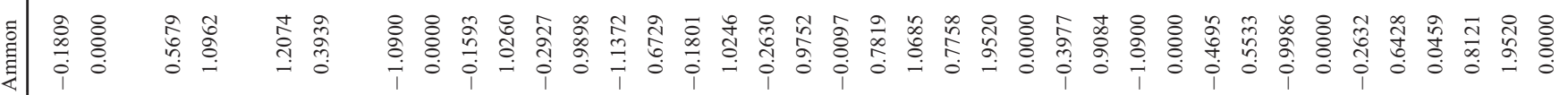

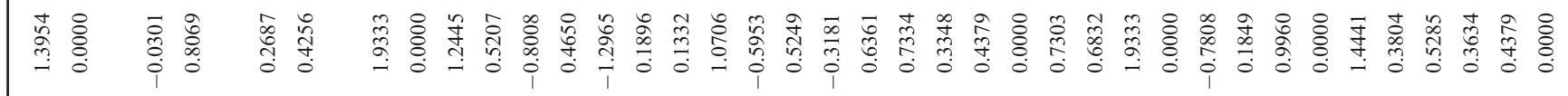

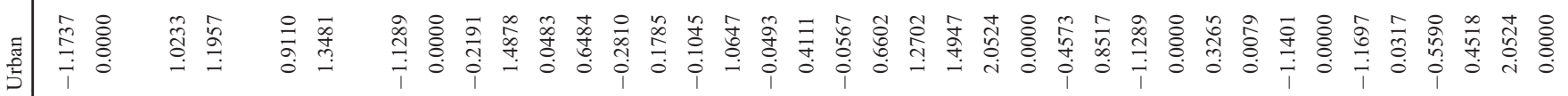

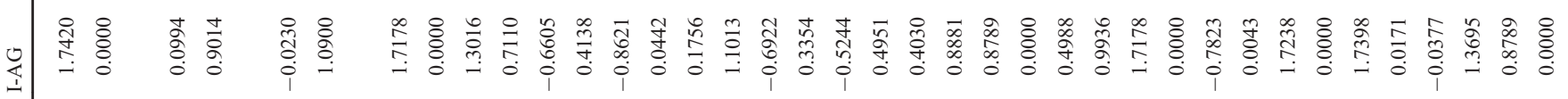

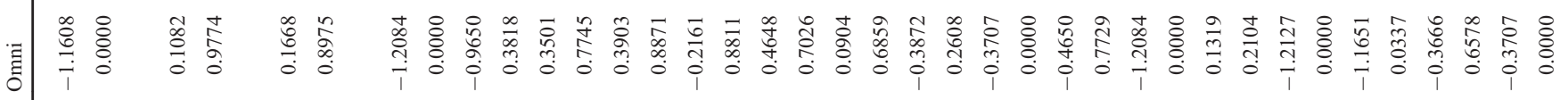

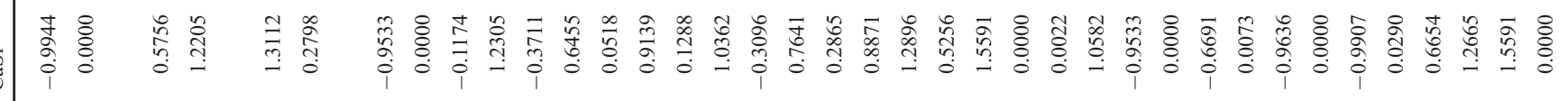

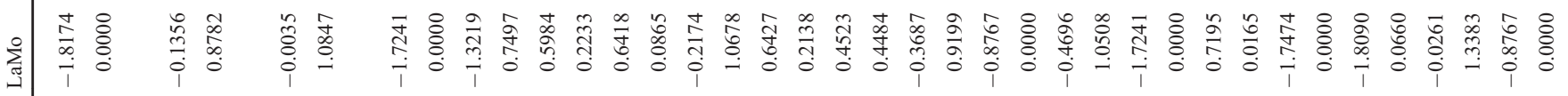

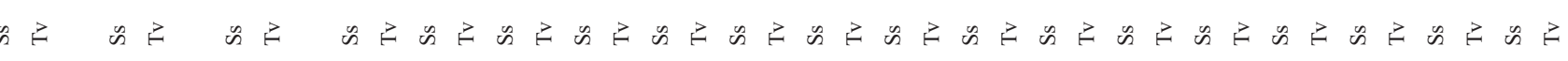

$\|1\|\|\|$ 
R. Šiling and G. Urbanič : Knowl. Manag. Aquat. Ecosyst. 2016, 417, 35

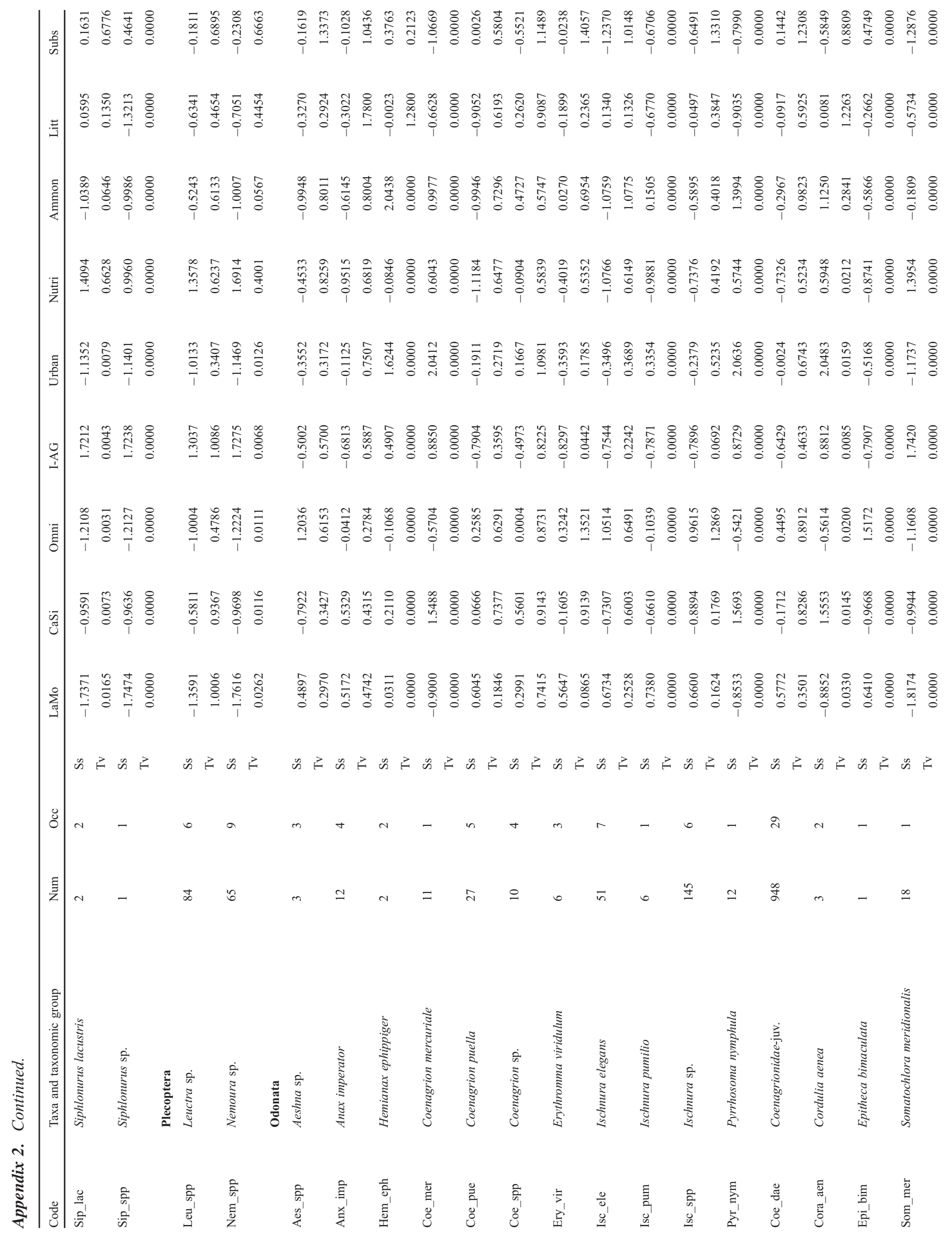


R. Šiling and G. Urbanič : Knowl. Manag. Aquat. Ecosyst. 2016, 417, 35

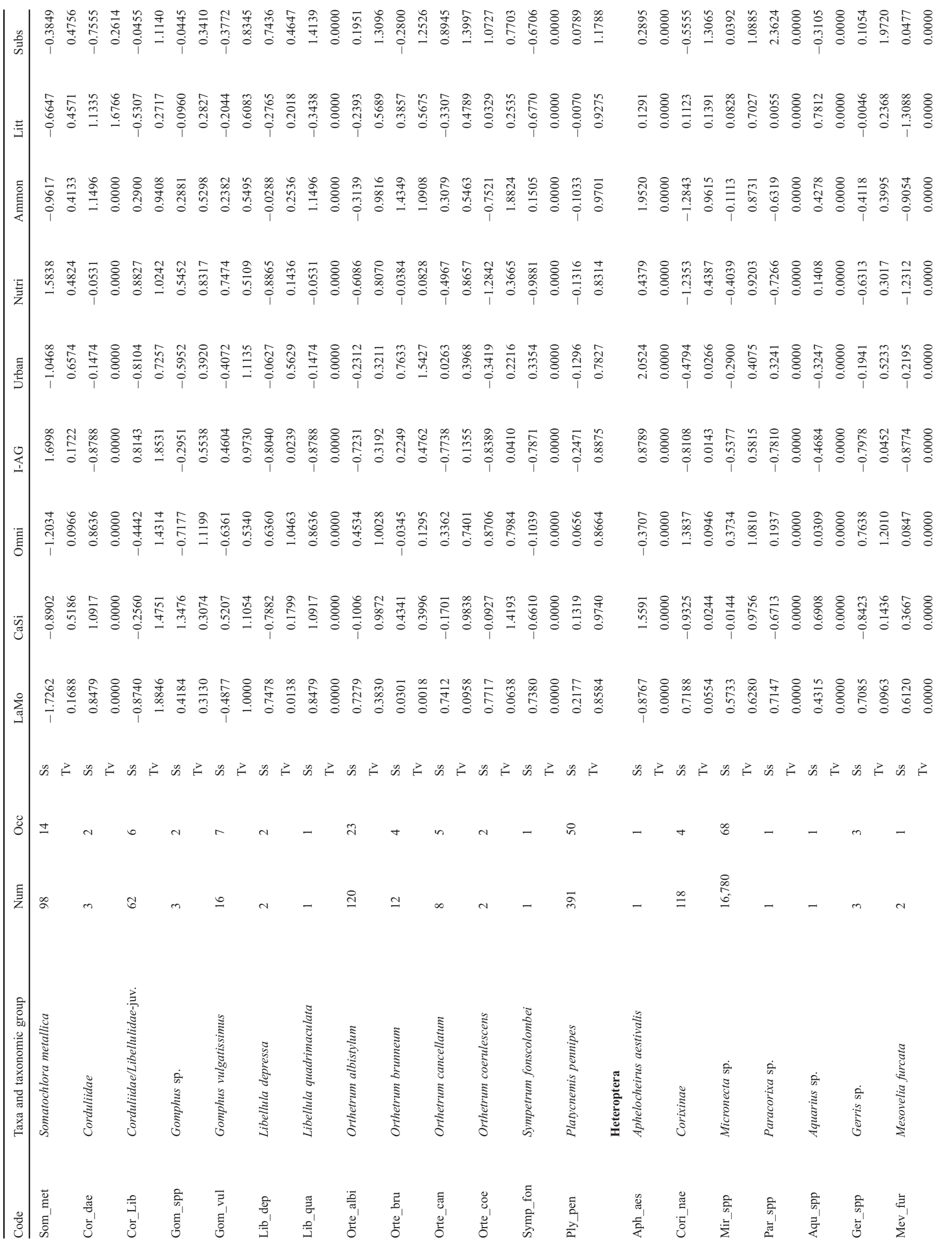


R. Šiling and G. Urbanič : Knowl. Manag. Aquat. Ecosyst. 2016, 417, 35

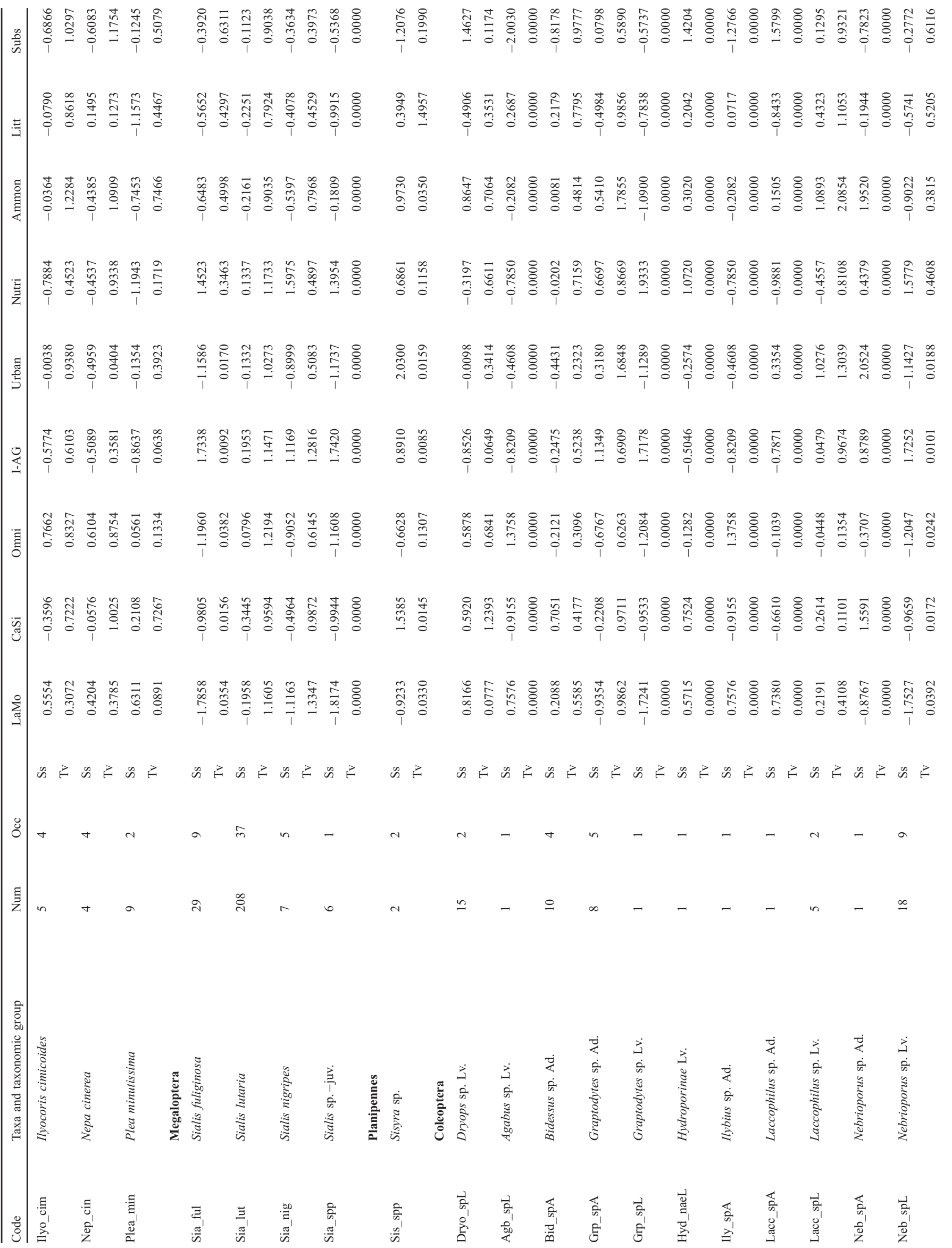


R. Šiling and G. Urbanič : Knowl. Manag. Aquat. Ecosyst. 2016, 417, 35

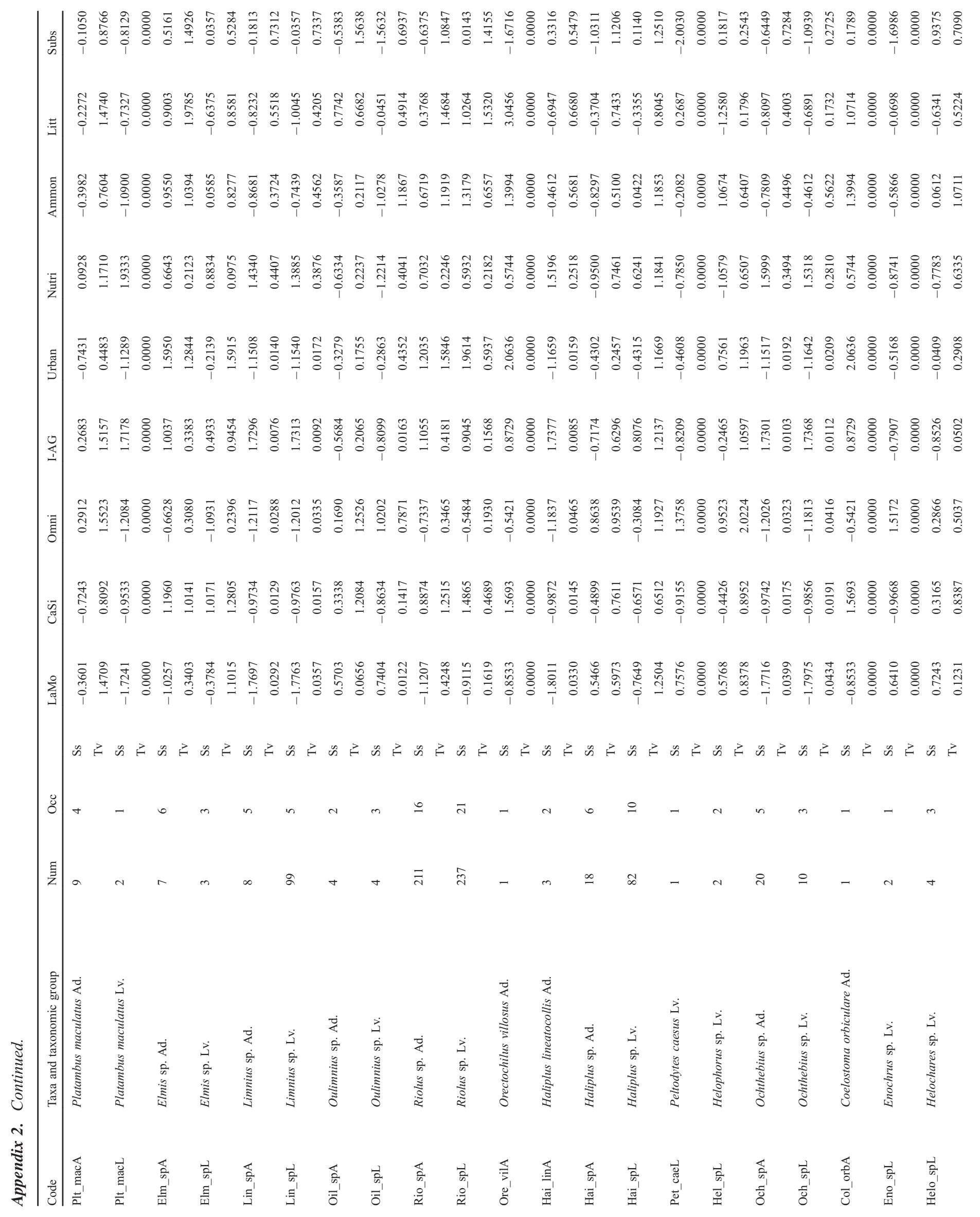


R. Šiling and G. Urbanič : Knowl. Manag. Aquat. Ecosyst. 2016, 417, 35

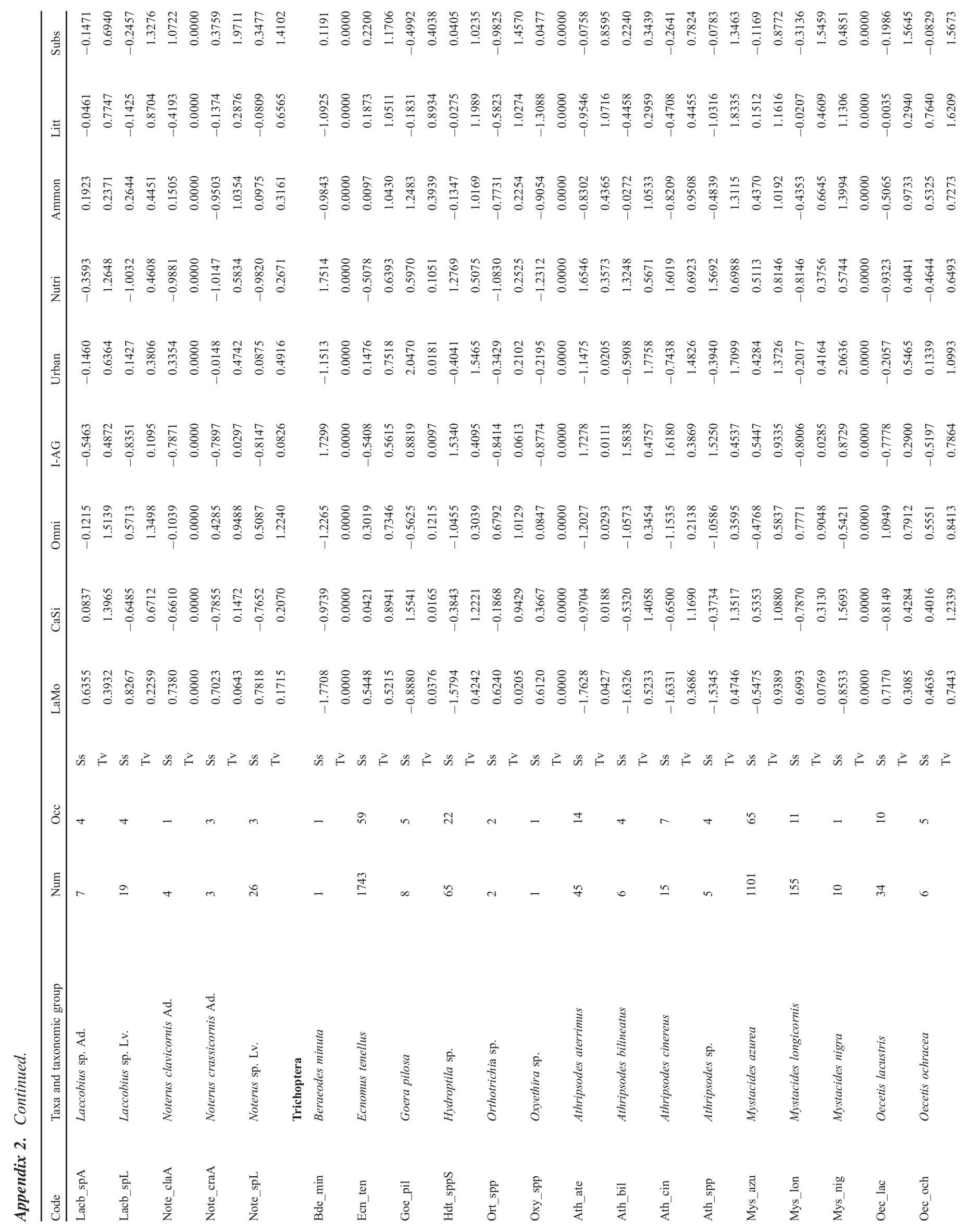


R. Šiling and G. Urbanič : Knowl. Manag. Aquat. Ecosyst. 2016, 417, 35

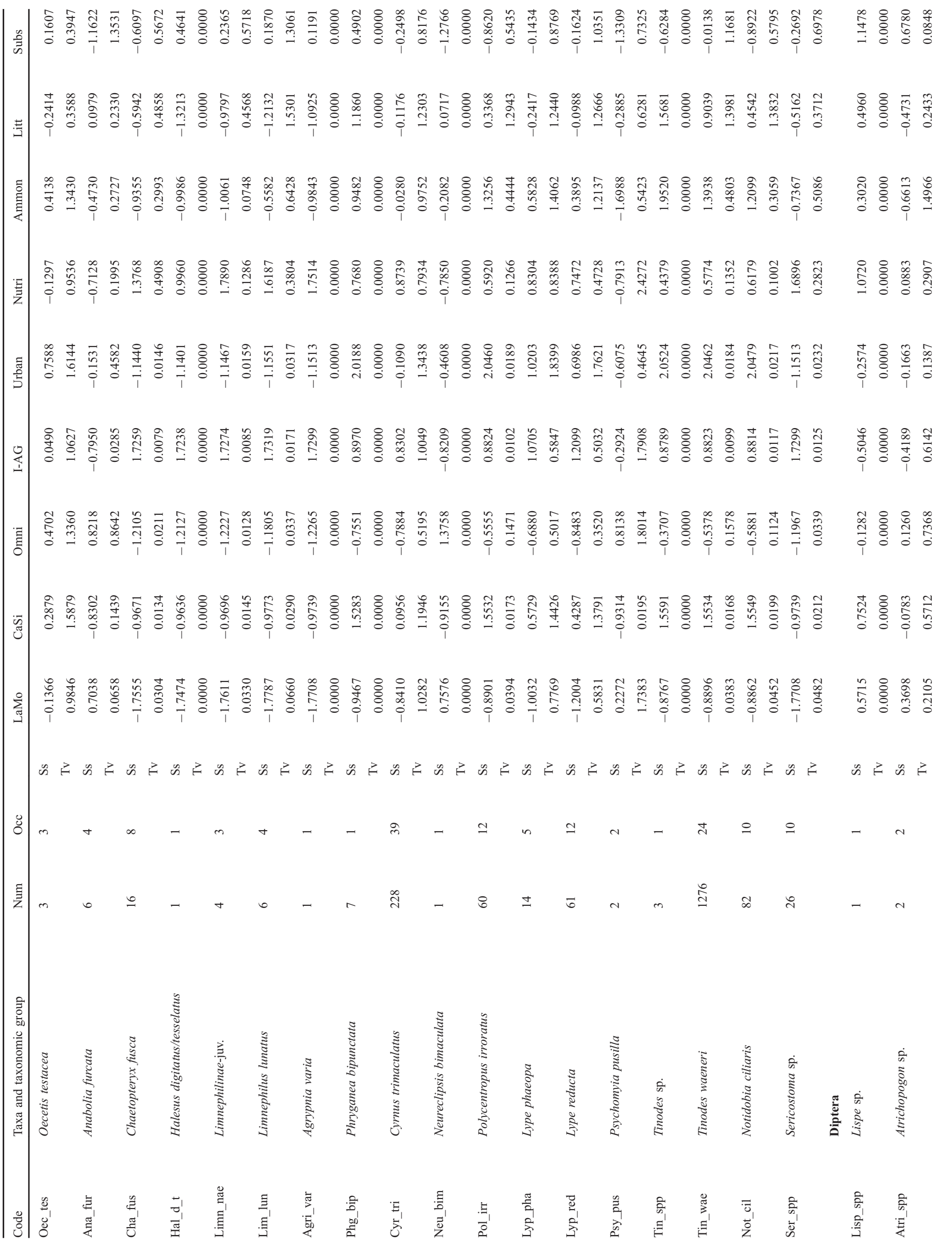


R. Šiling and G. Urbanič : Knowl. Manag. Aquat. Ecosyst. 2016, 417, 35

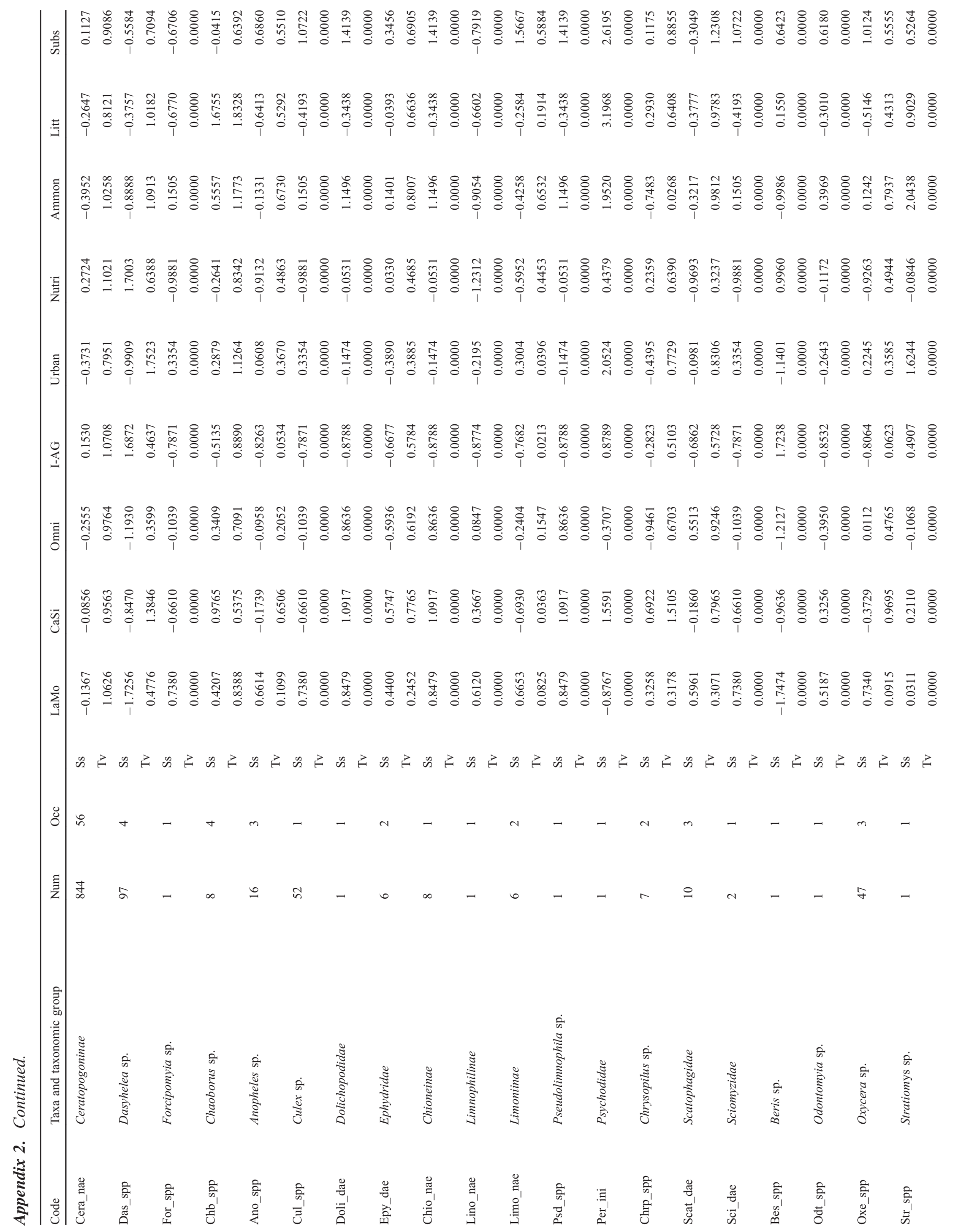


R. Šiling and G. Urbanič : Knowl. Manag. Aquat. Ecosyst. 2016, 417, 35

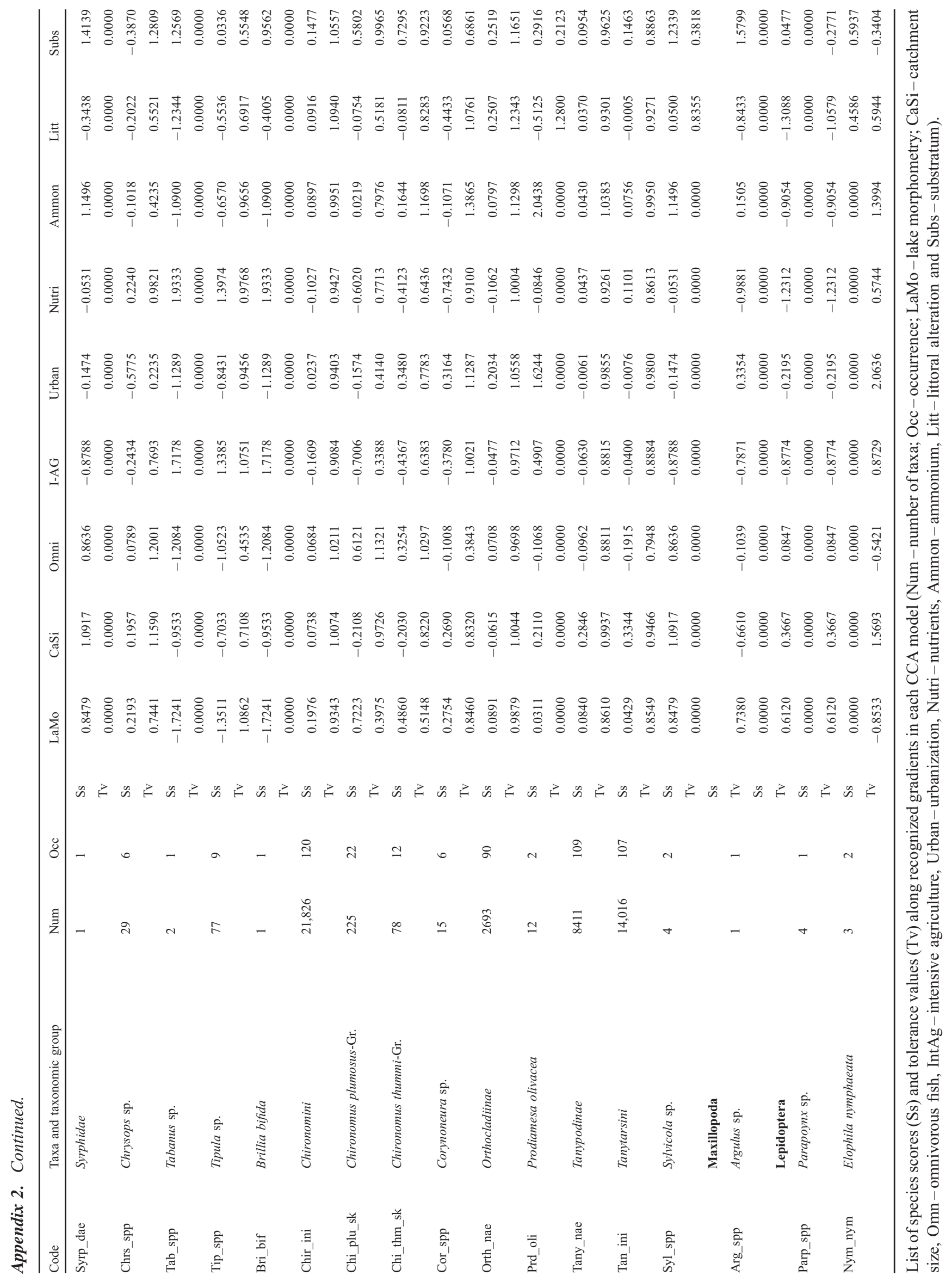




\section{Appendix 3}

Table of Friedmans test values with species scores and tolerance values.

\begin{tabular}{|c|c|c|c|c|c|c|}
\hline \multirow[t]{2}{*}{ Gradient $1-$ Gradient 2} & \multicolumn{3}{|c|}{ Results for indicator values } & \multicolumn{3}{|c|}{ Results for tolerance values ranges } \\
\hline & Test statistic $(Z)$ & Std. test statistic & Adj. sig. $(\rho)$ & Test statistic $(Z)$ & Std. test statistic & $\operatorname{Adj} . \operatorname{sig}(\rho)$ \\
\hline Urbanization-Littoral alteration & 0.998 & 4.099 & 0.001 & 0.709 & 2.914 & 0.129 \\
\hline Urbanization-Omnivorous fish & 1.508 & 6.193 & $<0.0001$ & -0.053 & -0.219 & 1.000 \\
\hline Ammonium-Urbanization & 0.753 & 3.092 & 0.071 & 0.771 & 3.165 & 0.056 \\
\hline Ammonium-Littoral alteration & 0.245 & 1.006 & 1.000 & -0.061 & -0.252 & 1.000 \\
\hline Ammonium-Omnivorous fish & 2.261 & 9.285 & $<0.0001$ & 0.717 & 2.946 & 0.116 \\
\hline Catchment size-Intensive agriculture & 1.636 & 6.720 & $<\mathbf{0 . 0 0 0 1}$ & -0.735 & -3.019 & 0.056 \\
\hline Catchment size-Nutrients & 1.532 & 6.290 & $<0.0001$ & -0.263 & -1.079 & 1.000 \\
\hline Catchment size-Ammonium & 0.881 & 3.620 & 0.011 & 0.403 & 1.656 & 1.000 \\
\hline Substratum-Catchment size & 1.844 & 7.573 & $<0.0001$ & 0.789 & 3.238 & 0.043 \\
\hline Substratum-Intensive agriculture & 0.208 & 0.852 & 1.000 & 1.524 & 6.258 & $<\mathbf{0 . 0 0 0 1}$ \\
\hline Substratum-Nutrients & 0.312 & 1.282 & 1.000 & 1.051 & 4.318 & 0.001 \\
\hline Substratum-Ammonium & 0.962 & 3.953 & 0.003 & 0.385 & 1.583 & 1.000 \\
\hline Substratum-Urbanization & 1.715 & 7.045 & $<0.0001$ & 1.156 & 4.748 & $<\mathbf{0 . 0 0 0 1}$ \\
\hline Substratum-Littoral alteration & 0.717 & 2.946 & 0.116 & 0.447 & 1.834 & 1.000 \\
\hline Substratum-Omnivorous fish & 3.223 & 13.238 & $<0.0001$ & 1.103 & 4.529 & $<\mathbf{0 . 0 0 0 1}$ \\
\hline Catchment size-Littoral alteration & 1.126 & 4.626 & $<0.0001$ & 0.342 & 1.404 & 1.000 \\
\hline Catchment size-Omnivorous fish & -1.379 & -5.665 & $<0.0001$ & -0.314 & -1.291 & 1.000 \\
\hline Catchment size-Urbanization & 0.128 & 0.528 & 1.000 & -0.368 & -1.510 & 1.000 \\
\hline Intensive agriculture-Littoral alteration & -0.510 & -2.094 & 1.000 & 1.077 & 4.423 & $<\mathbf{0 . 0 0 0 1}$ \\
\hline Intensive agriculture-Omnivorous fish & 3.016 & 12.386 & $<0.0001$ & -0.421 & -1.729 & 1.000 \\
\hline Intensive agriculture-Nutrients & -0.105 & -0.430 & 1.000 & 0.472 & 1.940 & 1.000 \\
\hline Intensive agriculture-Urbanization & -1.508 & -6.193 & $<\mathbf{0 . 0 0 0 1}$ & 0.368 & 1.510 & 1.000 \\
\hline Intensive agriculture-Ammonium & -0.755 & -3.100 & 0.070 & 1.138 & 4.657 & $<\mathbf{0 . 0 0 0 1}$ \\
\hline Nutrients-Ammonium & -0.650 & -2.760 & 0.273 & 0.666 & 2.735 & 0.224 \\
\hline Nutrients-Urbanization & 1.403 & 5.763 & $<\mathbf{0 . 0 0 0 1}$ & 0.105 & 0.430 & 1.000 \\
\hline Nutrients-Littoral alteration & -0.405 & -1.664 & 1.000 & 0.605 & 2.484 & 0.468 \\
\hline Nutrients-Omnivorous fish & 2.911 & 11.955 & $<\mathbf{0 . 0 0 0 1}$ & 0.051 & 0.211 & 1.000 \\
\hline Lake morphometry-Substratum & 1.761 & 7.232 & $<0.0001$ & 1.603 & 6.582 & $<\mathbf{0 . 0 0 0 1}$ \\
\hline Lake morphometry-Catchment size & -0.083 & -0.341 & 1.000 & 0.814 & 3.344 & 0.030 \\
\hline Lake morphometry-Intensive agriculture & 1.553 & 6.380 & $<0.0001$ & 0.079 & 0.325 & 1.000 \\
\hline Lake morphometry-Nutrients & 1.449 & 5.949 & $<\mathbf{0 . 0 0 0 1}$ & 0.551 & 2.264 & 0.848 \\
\hline Lake morphometry-Ammonium & 0.789 & 3.279 & 0.037 & 1.217 & 5.000 & $<\mathbf{0 . 0 0 0 1}$ \\
\hline Lake morphometry-Urbanization & 0.045 & 0.187 & 1.000 & 0.447 & 1.834 & 1.000 \\
\hline Lake morphometry-Littoral alteration & 1.043 & 4.285 & $<0.0001$ & 1.156 & 4.748 & $<0.0001$ \\
\hline Lake morphometry-Omnivorous fish & -1.462 & -6.006 & $<\mathbf{0 . 0 0 0 1}$ & 0.500 & 2.053 & 1.000 \\
\hline Littoral alteration-Omnivorous fish & 2.506 & 10.292 & $<0.0001$ & 0.656 & 2.695 & 0.254 \\
\hline
\end{tabular}

Bold values are statistically significant $(p<0.05)$. 